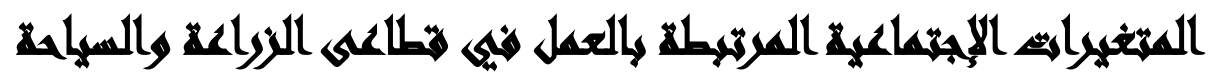

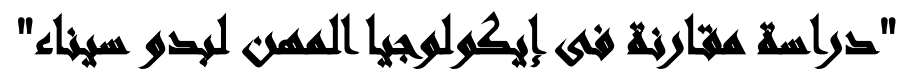

\section{[li}

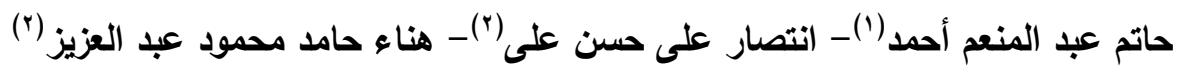

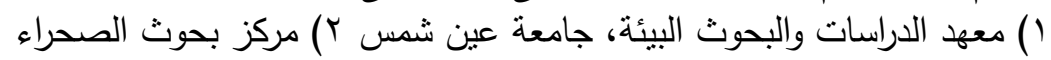

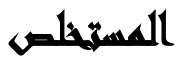

يهدف هذا البحث بصفة رئيسية دراسة المتغيرات الإجتماعية المرتبطة بالعمل بقطاعي

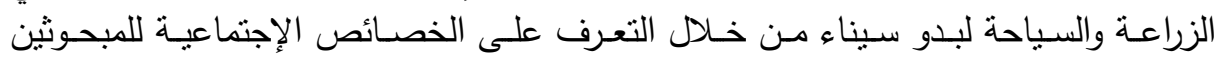

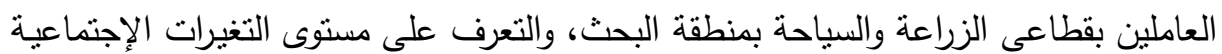

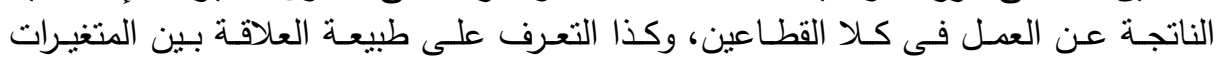

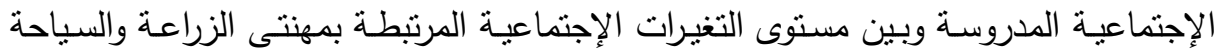
بمنطقة البحث.

ولتحقيق هذه الأهداف البحثية، تم إستخدام منهج المستح الإجتماعي بالعينة، وتم إختيار

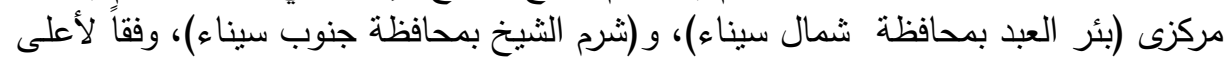

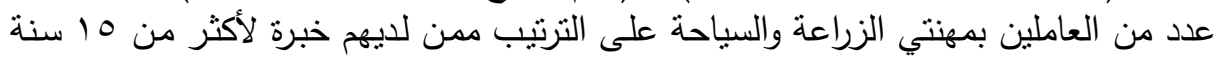

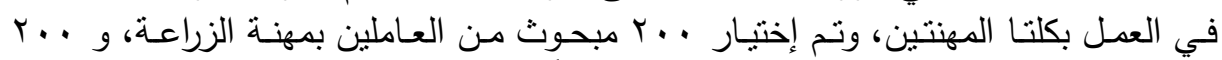

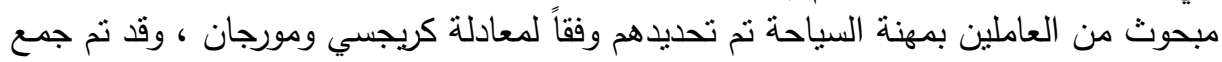

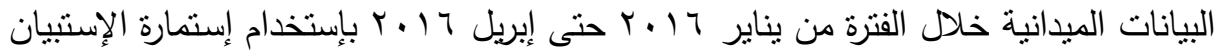

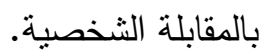
وأوضحت أهم نتائج البحث ما يلية المتئ

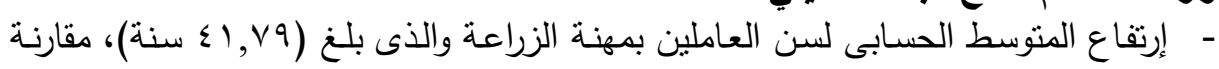

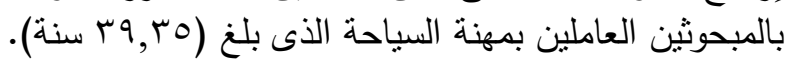

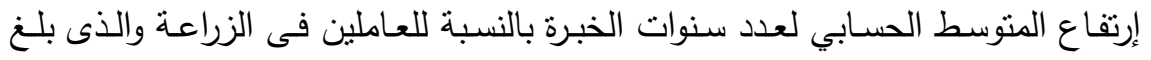

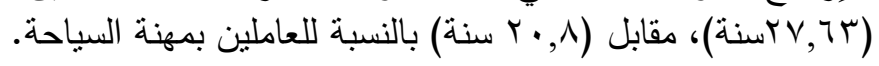

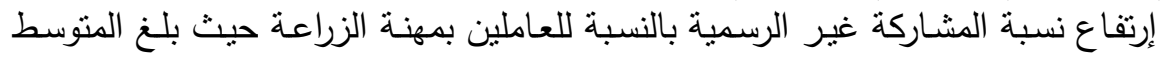

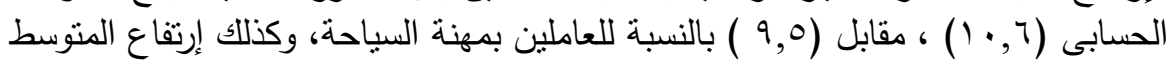

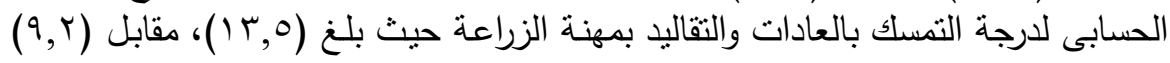
بمهنة السياحة . التابة 
- وجود فروق معنويـة بين منوسطى درجـة التغير الإجتمـاعى للمبحوثين العـاملين بمهنتى

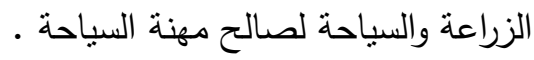

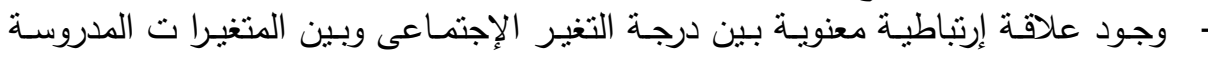

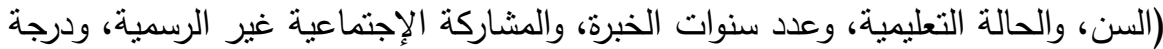
التمسك بالعادات والتقاليد) للمبحوثين العاملين بمهنتي الزراعة والسياحة. من أهم توصيات البحث ما يلي: - - بالنسبة لقطاع الزراعة: الإهنمام بالتسويق وإقامة الأسواق القريبة لجذب العبات العاملة إلى مهنة الزراعة، والتي تعد الأساس الأول لعملية التتمية.

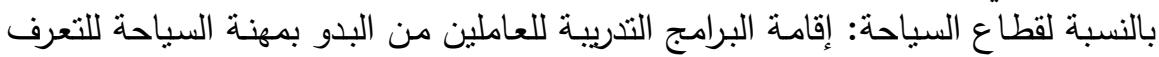

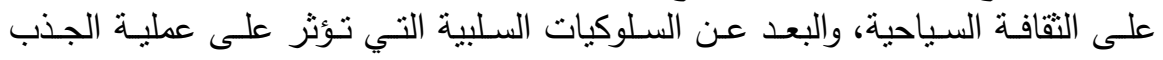

\section{ranodll}

يعنبر القطاع الزراعي أحد القطاعات الهامة في كثثر من الدول المتقدمة والنامية على حد سواء، وهو المورد الأساسي لغذاء وكساء الإنسان، وهو المسئول عن تزويد كثير من فن لهن

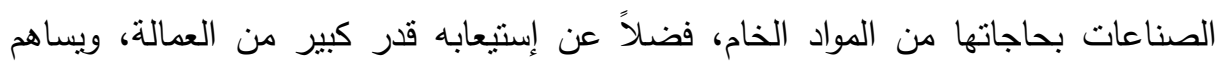

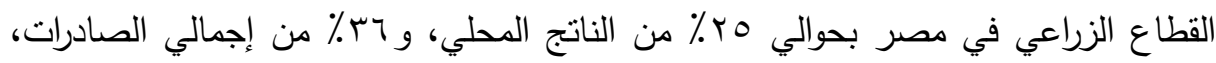

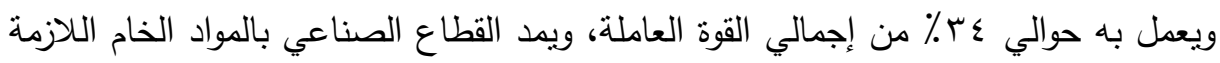

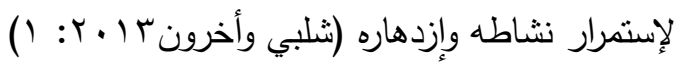
ويتميز القطاع السياحي أيضاً بدرجة كبيرة من الأهمية، وأحد أهم عناصر الدخل القدوري القدي المصري، حيث تعتبر السباحة سبب مباشر لاخول العملات الحرة البلاد، نتيجة بيع الخدمات ولهيه

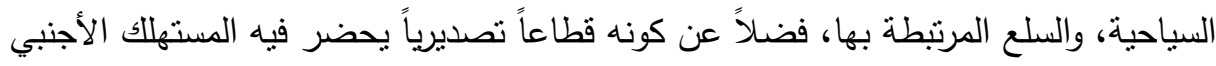
بحثًا عن المنتج أو الخدمة، ودون الحاجة إلى شحن أو تحرك مكاني للمنتج، كما لا تتطلب

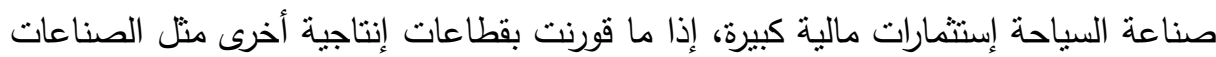
التعدينية أو الصناعة الثقيلة(Christie1990:34 Robert). 


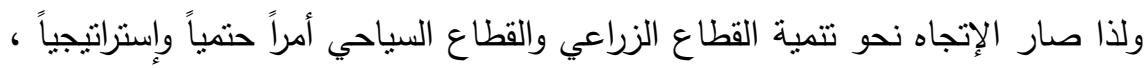

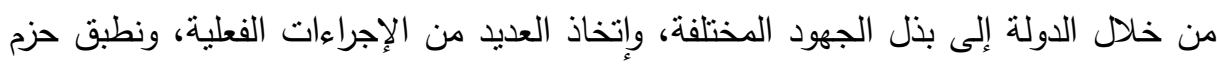
من السياسات والبرامج والإصلاحات اللازمة من أجل العمل على الوصول للهدف الرئيسي منهما، وهو تحقيق التتمية للمجتمع المصري بشكل عام. لإهن

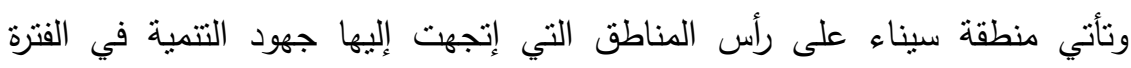
الأخيرة، بإعتبارها أهم محافظات الأمن القومي المصري، لما تتميز به من موقع جغرافي الفي يضفي عليها أهمية بالغة من الناحية الجغرافية، والسياسية فهي بوابة مصر الثرقية، وتمنتل العمق الإستراتيجي والحيوي، والدرع الواقي لمصر إضافة إلى إلى ماتحتويه من الإمكانيات الزراعية والسياحية المتوفرة بها ( محمد المغربي . . . ب : 79 ( ). ويشير مفهوم التغير الإجتماعي إلي التحول والإختلاف في فتره زمنية معينة فالتغير المخطط محاولة متعددة بواسطة فرد أو منظمة أو جماعة أو نظام إجتماعي يؤثز تأثثراً مباشراً

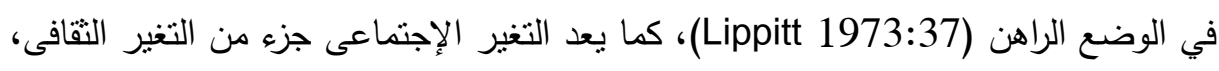

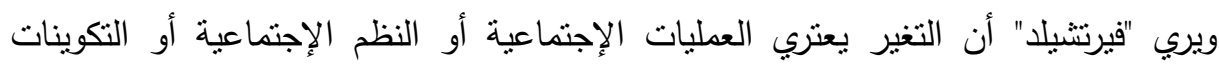

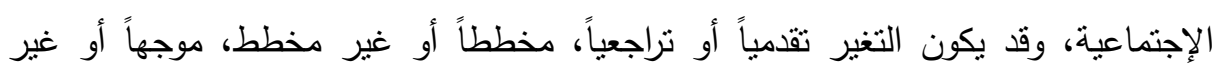

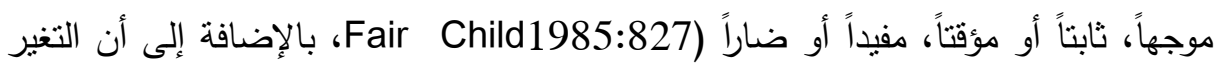

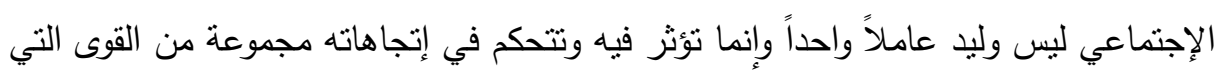

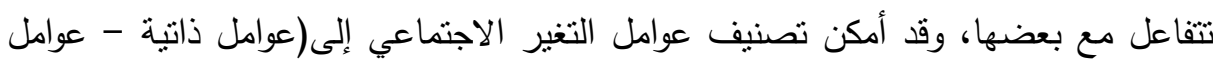

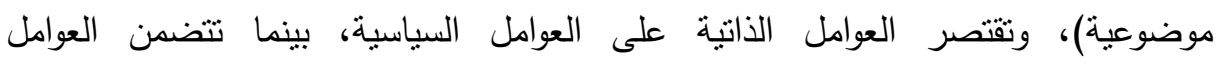

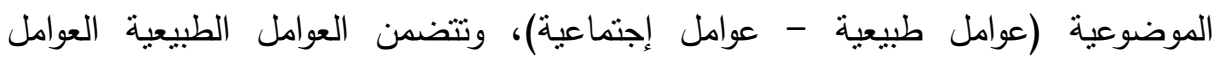

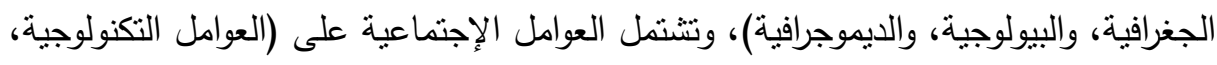

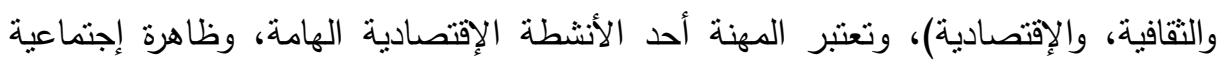

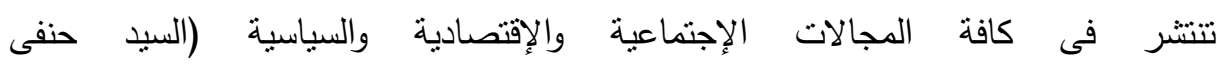

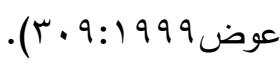




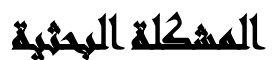

تعد منطقة سيناء من المناطق التي تشهد تغيرات إجتماعية لقاطنيها نتيجة تغير النشاط

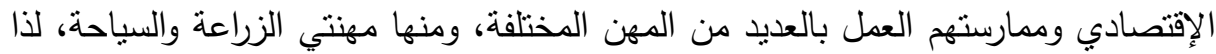
فقد تطلب الأمر دراسة أنز أيكولوجيا هاتين المهنتي الزراعة والسياحة على مستوى التغيرات التهن الإجتماعية لبدو سيناء للكثف عن نلك العوامل والمتغيرات التى تؤئر على عملية التغير الإجتماعى بمنطقة البحث، وقد لاحظت الباحثة نلك التغيرات من خلال العديد من الزيارات لمنطقة الدراسة بحكم طبيعة عملها كأخصائي إجتماعي بمركز بحوث الصحراء، والمشاركة

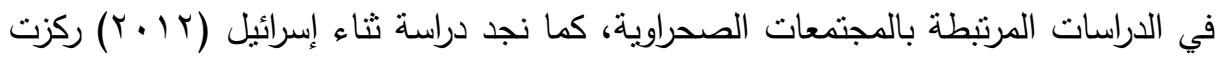
على العلاقة ما بين البشر ونشاطهم الإقتصادى، وركزت دراسة أحمد عبد الموجود الثناوي

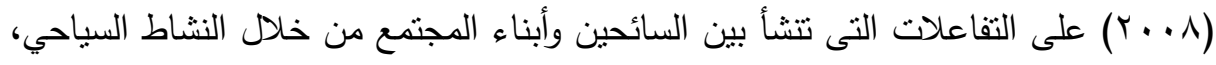

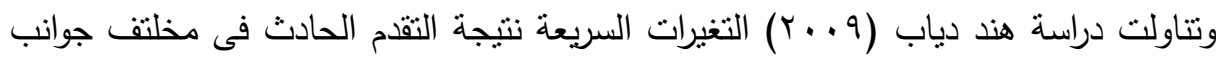
الحياه التكنولوجيا وخاصة جانب الإتصال والذى يؤثر بدوره على التغيرات الثقافية المادية

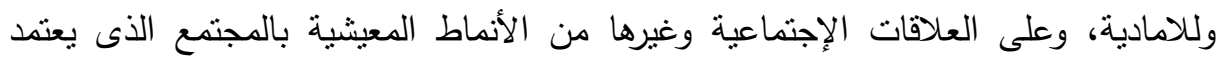

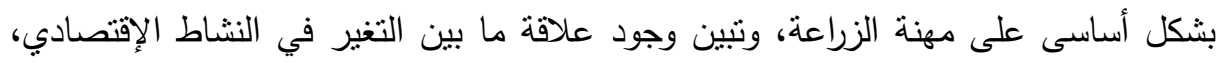
وتطور التكنولوجي، وبين حدوث تغيرات إجتماعية وثقافية سواء مادية وغير مادية.

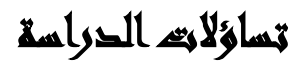

1- ما أهم التغيرات الإجتماعية المترتبة على إمتهان البدو لمهنتى الزراعة والسياحة بمنطقة

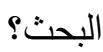
r- ما العوامل التى تؤثر على مستوى التغيرات الإجتماعية المرتبطة بالعمل بمهنتى الزراعة 


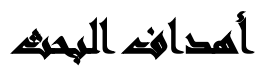

1- التعرف على الخصائص الإجتماعية للمبحوثين العاملين بكل من قطاعى الزراعة والسياحة بمنطقة البحث.

r- التعرف على مستوى التغيرات الإجتماعية الناتجة عن العمل فى قطاعى الزراعة والسياحة r- التعرف على طبيعة العلاقة بين المتغيرات الإجتماعية المدروسة وبين مستوى التغيرات الإتئه الإجنماعية المرتبطة بمهنتى الزراعة والسياحة بمنطقة البحث.

\section{هغوض الصواسة}

"توجد علاقة إرتباطية معنوية بين درجة التغير الإجنماعي من جهة وبين المتغيرات المدروسة للمبحوثين وهي: السن، والحالة التعليمية، وعدد سنوات الخبرة، والمشاركة الإجتماعية غير الرسمية، ودرجة التمسك بالعادات والتقاليد من جهة أخرى".

\section{أهمية التصواسم}

1. تكمن الأهمية في دراسة التغيرات التى تطرأ على المجتمعات البدوية نتيجة التغير فى الألى الأنشطة الإقتصادية، والإهتمام بالآثار الناتجة عن تطور لطنية الأساليب الزراعية والنطور

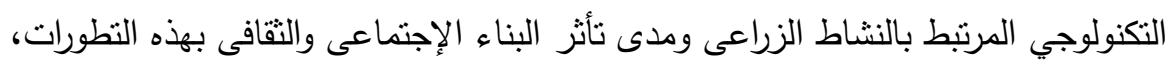

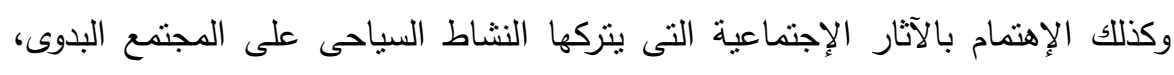
وتبثق هذه الدراسة من نموذج التكوين الإجتماعى المهني(أيكولوجيا المهن).

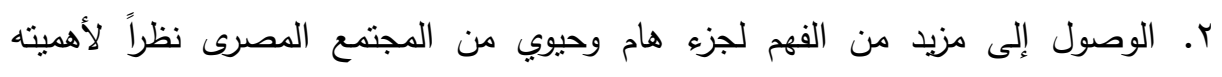
الإستراتيجية والسياسية والتتموية لمستقبل وأمن مصر ، وتنساعد واضعي الخدي الخطط التتموية

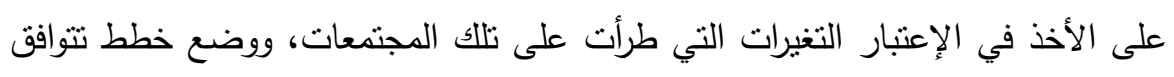
معها. 


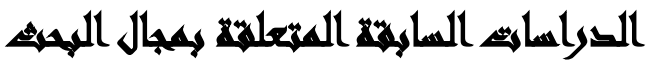

أ- الاراسات المتعلقة بالمتغيرات الإجتماعية المرتبطة بالعمل فى قطاع الزراعة

$$
\text { ويلغ عددها (r) دراسات يمكن تناولها على النحو التالي: }
$$

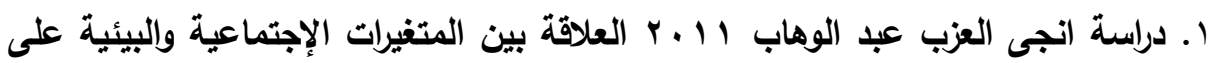

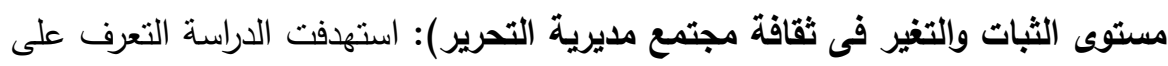

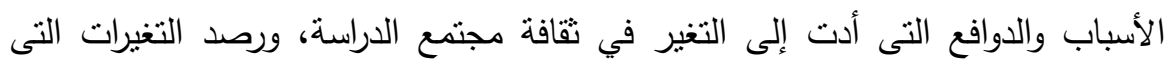

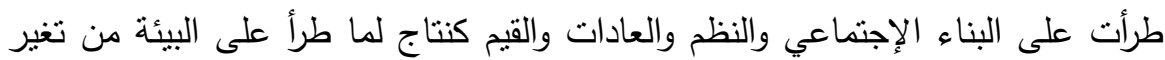

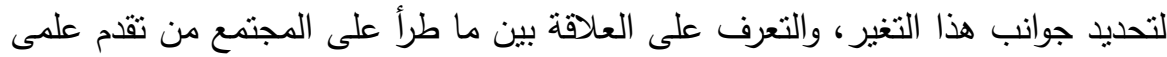
وتكنولوجى كنتاج للإنفتاح على النقافات الأخرى عبر وسائل الإتصال المختلفة وظهور أنماط ثقافية فى المجتمع لم تكن موجودة من قبل، والكثف على الآثار السلبية والإيجابية والنتائج الإجتماعية والثقافية المترتبة على التغيرات الإجتماعية والبيئية فى المجتمع

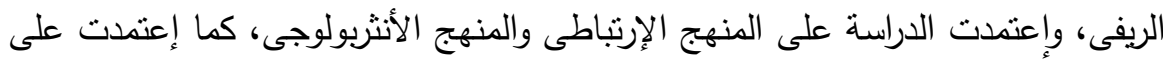
أدوات (المقابلة، والملاحظة، وإستمارة إستبيان، والإخباريين لجمع البيانات بمنطقة الدراسية

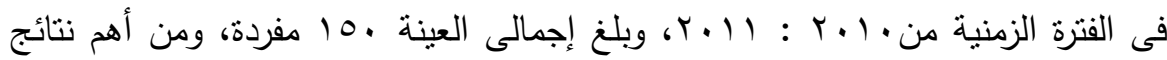

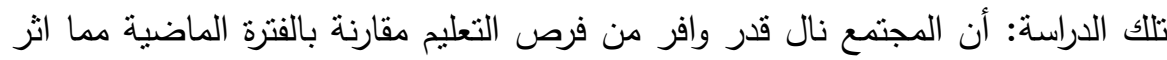

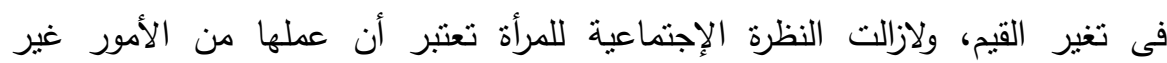

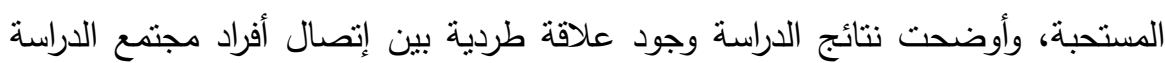

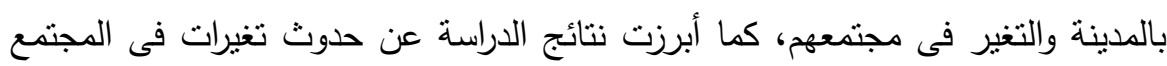
بشتى مجالاته، وأن التغيير له أوجه إيجابية وأخرى سلبية . r. دراسة (إنتصار على حسن 9. . . ب دراسة التغير الإجتماعي والثقافى المرتبط بتنمية المناطق الصحراوية دراسة ايكولوجية فى واحة سيوه): استهدفت الدراسة تحليل دينامية عملية التغير من النواحى الإجتماعية والإقتصادية والثقافية والسياسية والبيئية والخدمية كنتيجة لتنفيذ المشروعات التتموية بواحة سيوه، وإعتمدت الدراسة على منهج المسح الإجتماعى بطريقة العينة العشوائية البسيطة والمنهج المقارن، وإستخدمت الدراسة (المقابلة 


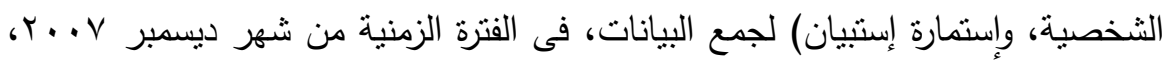

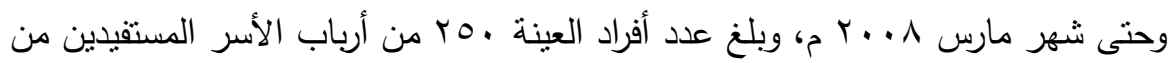

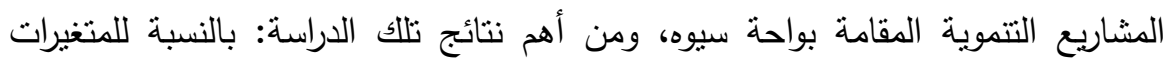
الإقتصادية تبين أن ثلثى العينة مستوى حالة مساكنهم بين المنخفض والمتوسط، وبالنسبة ولنية للمتغيرات الإجتماعية أسفرت النتائج أن دوافع المشاركة الإجتماعية الرسمية وغير الرئه الرسمية

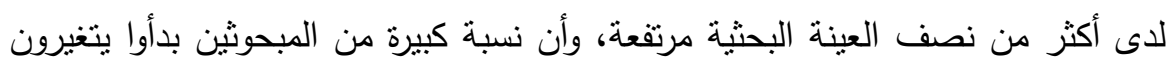

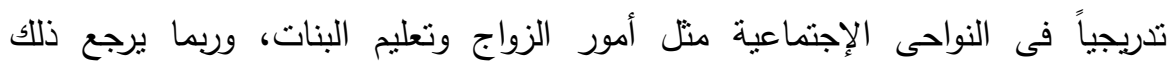
لإنفتاحهم الثقافى على العالم الخارجى ومشاركتهم فى المشروعات التنموية. r. دراسة ( محمود حسن ضيف ه ... التغيرات الإجتماعية فى الأسر السيناوية الناتجة عن التنمية بشمال سيناء ) استهدفت الدراسة تحديد التغيرات البنائية فى الأسر السيناوية الناتجة عن تتفيذ بعض مشروعات التتمية، وتحديد مستوى التغيرات الوظيفية فى تلك الك الأسر الناتجة عن تتفيذ بعض مشروعات التتمية، وتحديد العلاقة بين معرفة المبحوثين

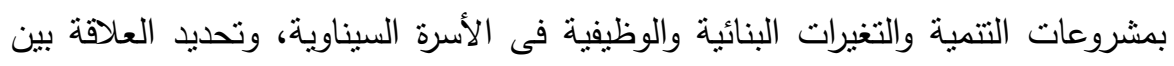
إستفادة المبحوثيين من مشروعات التتمية والتغيرات البنائية والوظيفية فى الأسرة السيناوية، ولئه إعتمدت الدراسة على منهج المسح الإجتماعى بالعينة، وإستخدمت(المقابلة الثخصية،

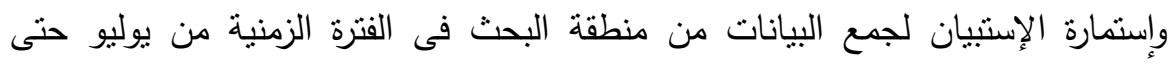

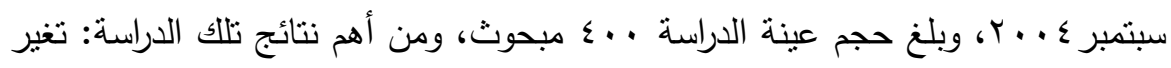

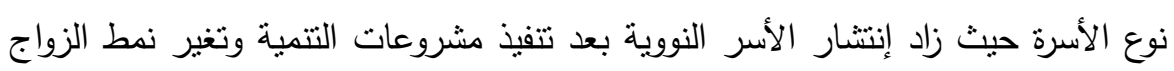

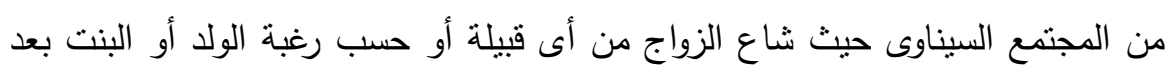

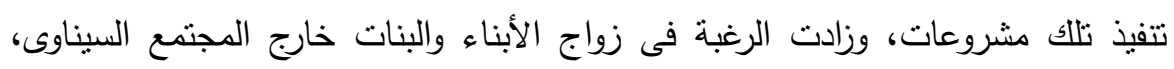

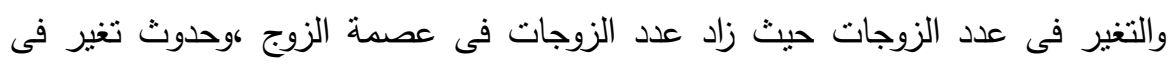

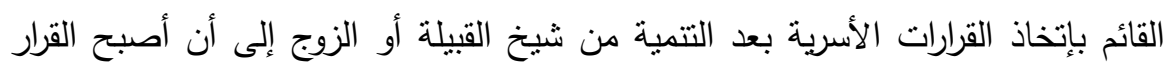

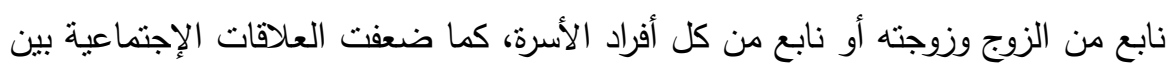
الأفراد والأسر ، وأوضحت النتائج زيادة قيام الأسرة بتعليم الأبناء التعاون مع التهن الآخرين

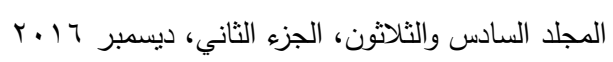


والمحافظة على المثنكات العامة، وحدوث إنخفاض فى إحترام تقاليد المجتمع السيناوى،

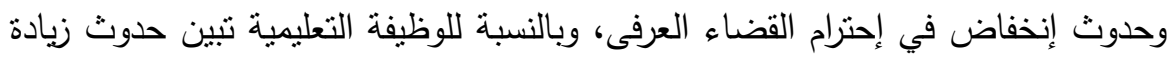
فى الأنشطة التعليمية بعد التتمية منل إلحاق الأبناء بالتعليم والحرص على ولى إستكمال

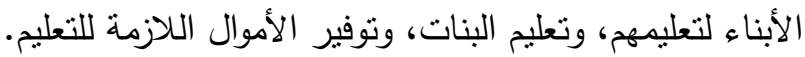

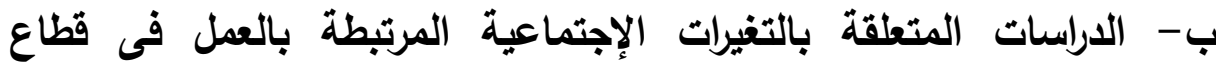
السياحة، ويلغ عددها (r) دراسات، أمكن تناولها على النحو التالي: ا. دراسة ثناء إسرائيل r r ب المتغيرات الديموجرافية والإجتماعية المرتبطة بإستخدام الموارد البيئية فى جنوب سيناء: استهدفت هذه الدراسة التعرف على العلاقة ما بين البشر ونشاطهم الإقتصادى، وعرض المتغيرات الديموجرافية والمتغيرات الإجتماعية لسكان محافظة جنوب سيناء، والتعرف على التغيرات الإجتماعية التى حدثت فى المجتمع البدوى الإنى منذ تحرير سيناء، استعانت الدراسة بأكثر من منهج ( المنهج الإستقرائى، والمنهج الوصفى، ومنهج المسح الإجتماعى، والمنهج العلىى المقارن، إستخدمت الدراسة (الوثائق والسجلات الرسمية والمقابلة المتعمقة والملاحظة العلمية) لجمع البيانات من منطقة الدراسة والماتهات

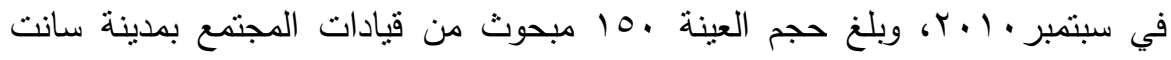

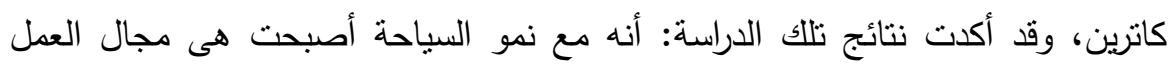
الرئيسى للبدو، وأصبح البدوى يرفض العمل فى الأنشطه الإقتصادية الأخرى لضآلة

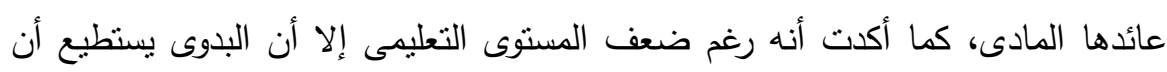
يتحاور مع السائحين بأكثر من لغة الغة.

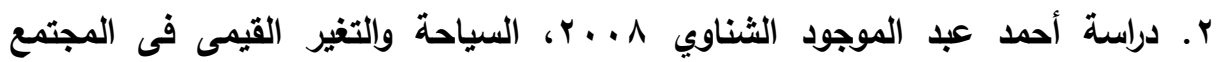
البدوى - مجتمع ذهب نموذجاً: استهدفت الدراسة رصد أنثكال ومجالات التفاعل بين أبناء المجتمع البدوى وبين السائحين، والكثف عن الأثنار التى يحدثها ذلك التفاعل على التى القيم البدوية التقليدية ودوره فى خلق قيم جديدة فى المجتمع البدوى، والتعرف على أهم القيم

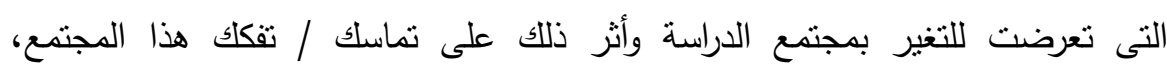

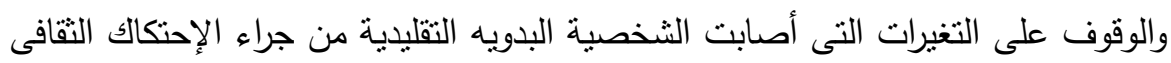


مع السائحين، والتعرف على مدى وعى وإدرالك أبناء المجتمع البدوى بعملية التغير القيمى

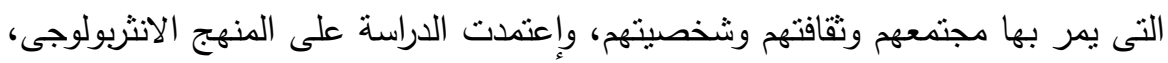

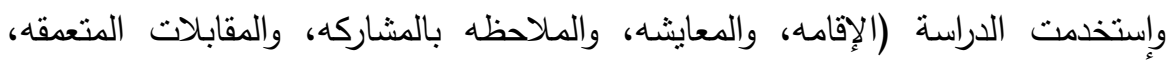

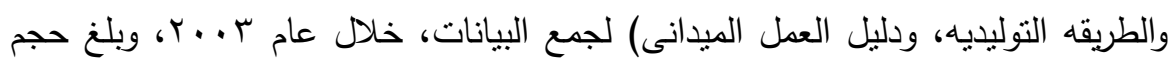

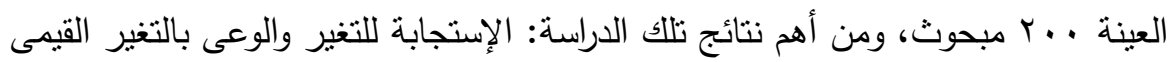

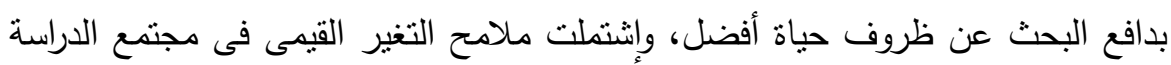
في (لإستقرار والتمدن النسبى، وتراجع دور القانون العرفى)، كما ظهرت ملامح التغير القيمى فى خصائص مجتمع الدراسة تمنلت في (إنساع عملية التغير، وتراجع العلاقات دورن

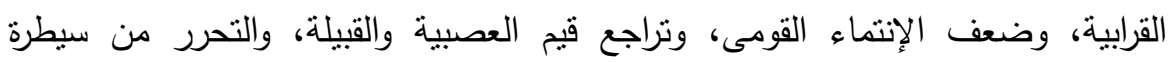

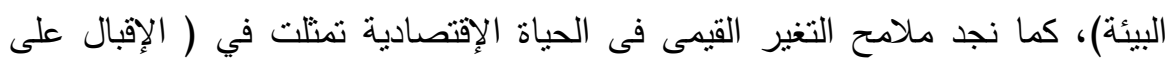
العمل، وتغير مصادر الدخل وقيم الإنفاق)، كما ظهرت ملامح التغير القيمى فى عنى عناصر الإهر

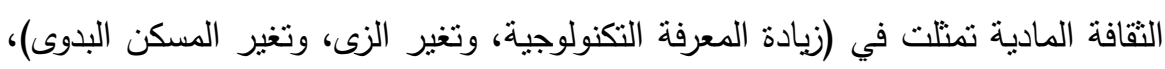
وملامح التغير القيمى فى الثخصية البدوية تمثلت في (تغير نظرة البدو للعمل اليدوى، وتراجع تقدير كبار السن، وتغير معايير المكانة، وتراجع قيم الكرم والضيافة، وتغير النظرة

$$
\text { غير المحدودة للوقت والمسافة). }
$$

r. دراسة عبير عبد الرحمن ؟ . . ب التتمية السياحية وأثرها على الحياة الإجتماعية -

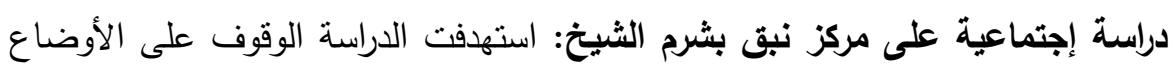

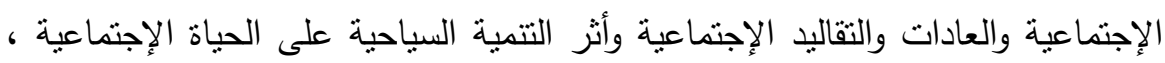
وإعتمدت الدراسة على منهج المسح الإجتماعى بطريقة العينة، وإستخدمت الدراسة إلهاءئه

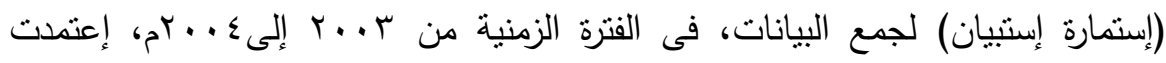

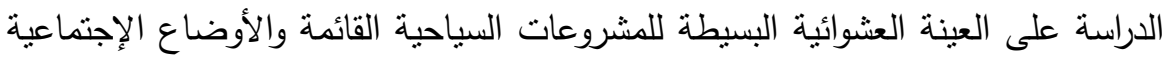

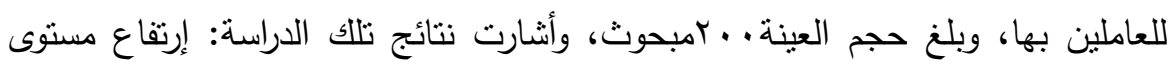

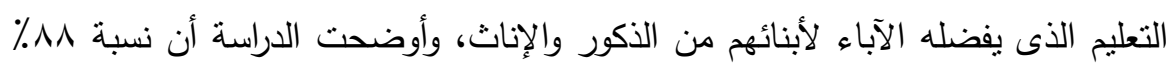
من جملة عينة الدراسة نرغب فى تعليم أبنائهم حتى مستوى الجامعة، وأن هناك إرتفاعاً

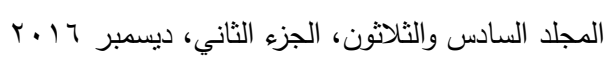


ملحوظاً للمكانة الإجتماعية للمرأة من خلال مشاركتها لرأي الزوج فى الحياة الأسرية،

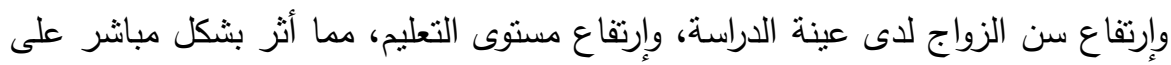

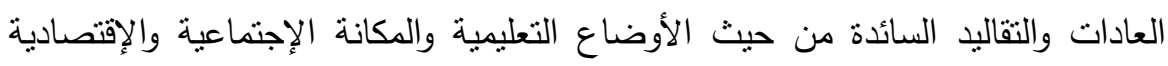

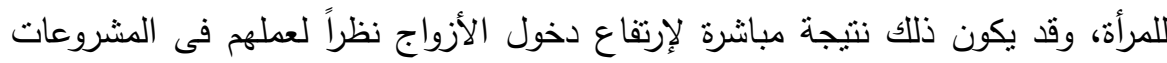
السياحية.

\section{هماسمير المهAه}

ايكولوجيا المهن: إن المهنة تطبع صاحبها بعدة صفات معينة بمعنى أن هذا الثخص إذا عمل فى مهنة أخرى مدة طويلة سوف يتغير سلوكه غالباً ، وتختلف هذه الصفات بإختلاف

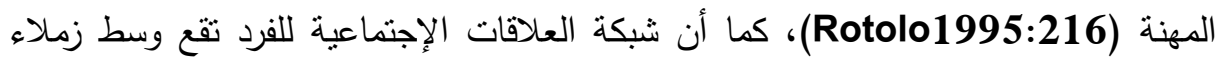

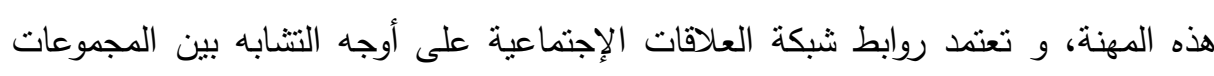

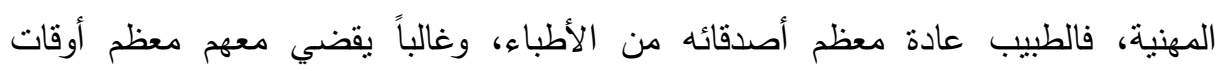
حياته(Keller1996:141)، بل تمند هذه العلاقات إلى أوقات الفراغ ويقضوا معظم أوقات

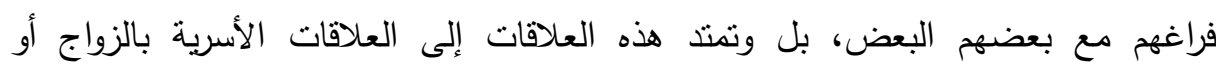

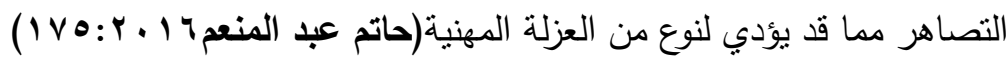

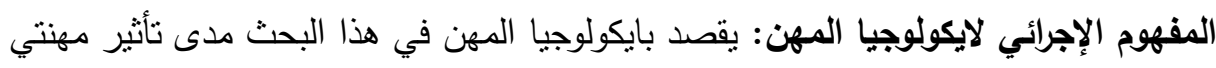

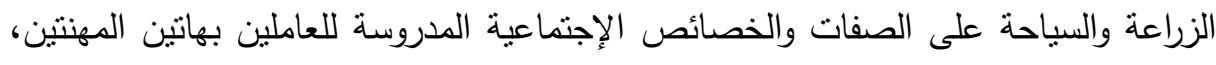

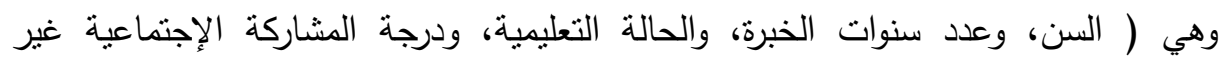
الرسمية، ودرجة التصسك بالعادات والثقاليد)، ومدى تأثيرها أيضاً على درجة التغير الإجتماعي ودئه

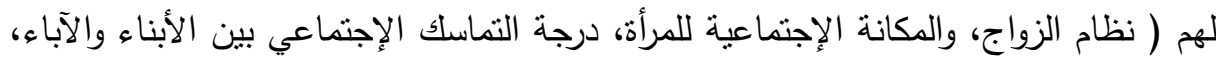
ودرجة الإنتماء القبلي) بمنطقتي شمال وجنوب سيناء. 


\section{الإجباءايت المنهجيه}

1 - منهج البحث: تعد هذه الدراسة من الدراسات الوصفية التحليلية، حيث أن جزء منها يتتاول وصف متغيرات الدراسة، أما الجانب التحليلي في الدراسة فيختص بإختبار الفروض النظرية للاراسة التي تختص بالعلاقة بين المتغيرات المستقلة المدروسة والمتغيرات التابعة، وإعتمدت الدراسة على منهج المسح الإجتماعي بالعينة، لوصف عينة الدراسة من ناحية، وتحقيق أهداف البحث وفروضه من ناحية أخرى.

r - أدوات جمع البيانات: اعتمد البحث على مصدرين للحصول على البيانات: أولهما

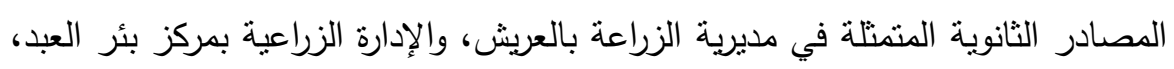
بمحافظة شمال سيناء، ومكتب تتشيط السياحة بمركز شرم الثيخ، وإدارة السياحة، لئل بمحافظة جنوب سيناء، وذلك للحصول على البيانات المتعلقة بتحديد عينتي البحث. أما ثاني هذه المصادر فيتعلق بالبيانات الححقة لأهداف البحث، والتي جمعت من لهن

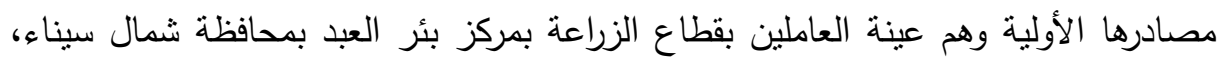

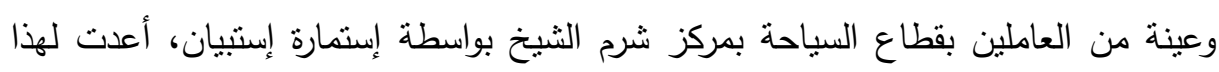
الغرض.

وتألفت إستمارة الإستنيان التى إستخدمت في هذا البحث من جزئين رئيسين، أولهما:

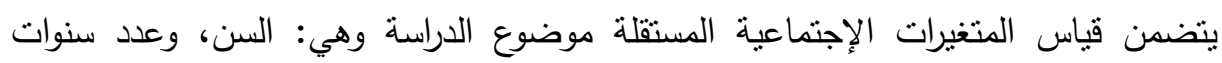

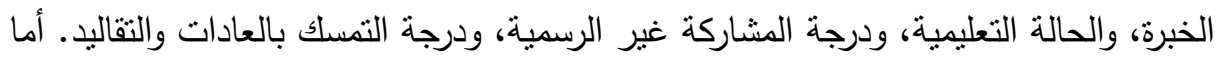
ثانيهما: فهو قياس المتغيرات التابعة موضع الدراسة وهو درجة التغير الإجتماعي، ونت قياسه من خلا نظام الزواج، والمكانة الإجتماعية للمرأة، ودرجة التماسك الإجتماعي بين الآبناء والآباء، ودرجة الإنتماء القبلي. ولتوصل إلى الدلالة الخاصة بثبات الأداة المستخدمة، تم إستخدام معادلة

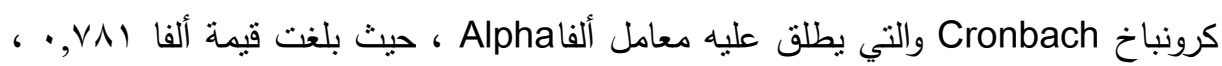
ويعتبر ذلك دليل على ثابتها. 


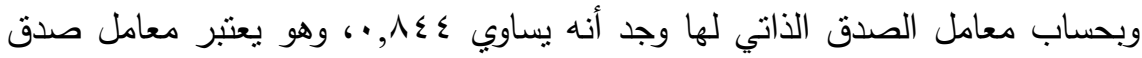

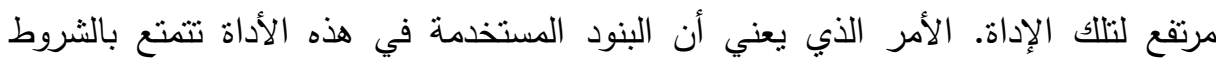
الواجب نوافرها في أداة القياس المناسبة والموثوقة. صدق التحكيم: تم عرض إستمارة الإستبيان الخاصة بتجميع بيانات هذا البحث في صورتها

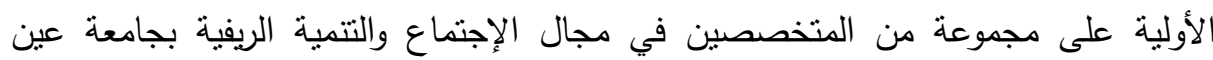

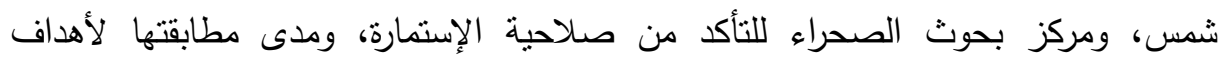

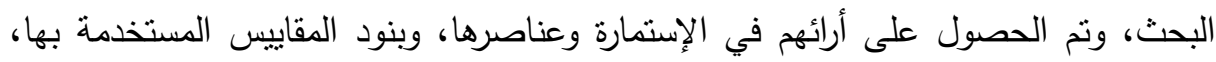

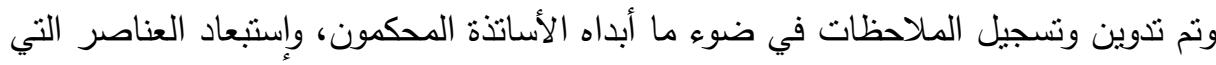

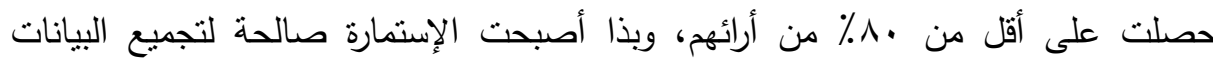
الميدانية في صورتها الحالية. r- عينة البحث: لما كان هذا البحث يستهف دراسة المتغيرات الإجتماعية المرتبطة بالعمل بقطاعى الزراعة والسياحة لعينة من بدو سيناء فإنه يمكن تتاول شاملة البحث من

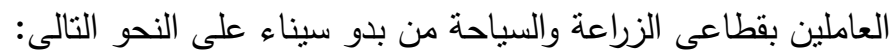

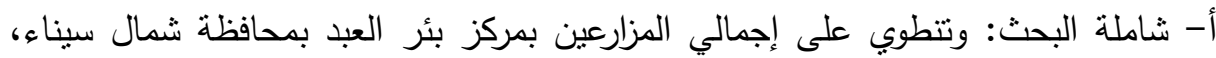

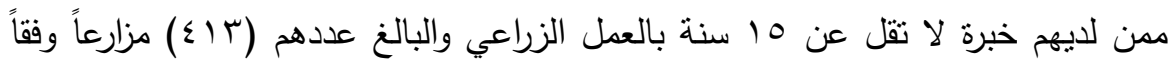
لبيانات مديرية الزراعة بالعريش والإدارة الزراعية بمركز بئر العبد.

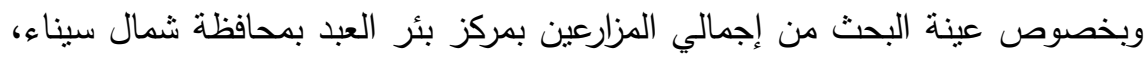

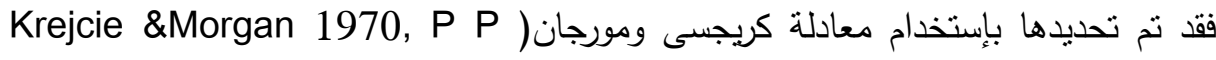

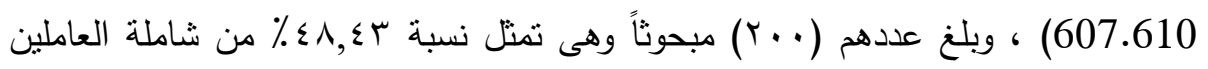
بقطاع الزراعة بمركز بئر العبد بمحافظة شمال سيناء، نم إختيارهم بطريقة عشوائية بسيطة

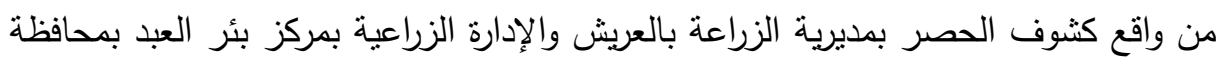
شمال سيناء. ب- شاملة البحث تتطوى على العاملين بقطاع السياحة بمركز شرم الثيخ بمحافظة جنوب

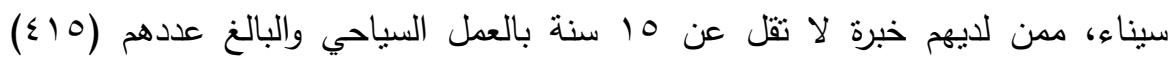


عاملاً، وفقاً لبيانات مكتب تتشيط السياحة بشرم الثيخ، وإدارة السياحة بمحافظة جنوب سيناء

وبخصوص عينة البحث من العاملين بقطاع السياحة بمركز شرم الثيخ بمحافظة جنوب

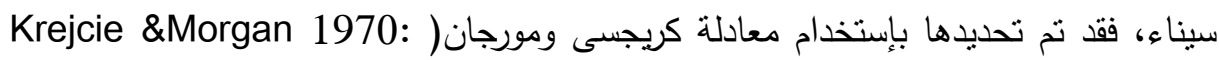

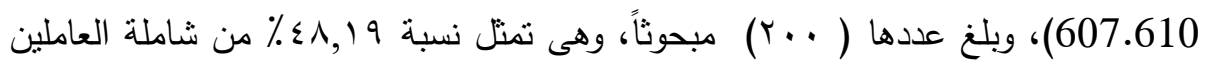
فى قطاع السياحة بمركز شرم الثيخ بمحافظة جنوب سيناء، وتم إختيارهم بطريقة عشوائية بسيطة من واقع كثوف الحصر بمكتب تتشيط السياحة بشرم الثيخ وإدارة السياحة بمحافظة جنوب سيناء. ع - مجالات الاراسة: وبتضاء

أ- المجال الجغرافى: تم تحديد المجال الجغرافى للدراسة والمتمنل فى مركز بئر العبد حيث يضم أكبر عدد من العاملين بمهنة الزراعة بمحافظة شمال سيناء، ومركز شرم الثيخ

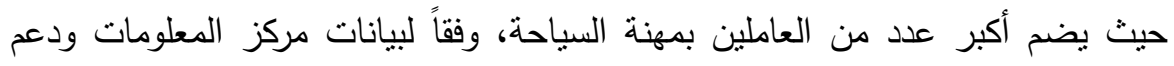
إتخاذ القرار بالمحافظتين.

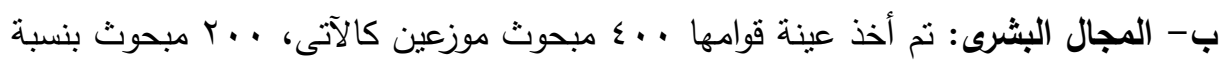

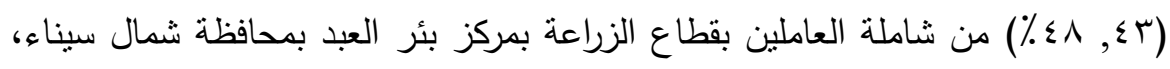

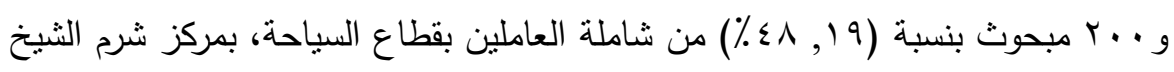
بمحافظة جنوب سيناء.

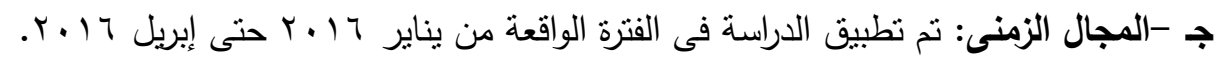




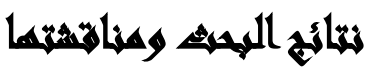

$$
\text { يمكن عرض نتائج البحث على النحو التالي: }
$$

أولاً: النتائج الخاصة بالخصائص الإجتماعية للمبحوثين

جدول رقم(1): توزيع المبحوثين وفقاً للخصائص الإجتماعية

\begin{tabular}{|c|c|c|c|c|}
\hline \multicolumn{2}{|c|}{ العاملين بالسياحة } & \multicolumn{2}{|c|}{ العاملين بالزراعة } & \multirow[b]{2}{*}{ المتغيرات المدروسة } \\
\hline$\%$ & ن = عد. r & $\%$ & ن =. ع. r & \\
\hline \multicolumn{5}{|c|}{ لفئات السن } \\
\hline$\varepsilon \cdot, \cdot$ & A. & $\varepsilon \cdot 0$ & NI & מن 0Y إلى أقل من צr \\
\hline$r \cdot, \cdot$ & 7. & $T V, 0$ & ro & من צب ألى أقل من V \\
\hline$r \cdot, \cdot$ & 7. & $\varepsilon r, \cdot$ & $\Lambda \varepsilon$ & من ك ف فاكثر \\
\hline \multicolumn{2}{|c|}{ r } & \multicolumn{2}{|c|}{$\varepsilon 1, \vee 9$} & المتوسط الحسابي \\
\hline \multicolumn{2}{|c|}{$T \cdot, T$} & \multicolumn{2}{|c|}{$\Pi, \leqslant \Lambda$} & الإنحراف المعياري \\
\hline \multicolumn{5}{|c|}{ الحالة التعليمية } \\
\hline TVQ. & $\Gamma \varepsilon$ & $\cdot \square \leqslant r$ & ベ் & امد \\
\hline OQTर & §0 & $\cdot \frac{\mathrm{DIV}}{\mathrm{V}}$ & $r \varepsilon$ & أقل من المتوسط \\
\hline YTQO & or & $r \Delta[0$ & $\overline{V I}$ & ت نانوى / دبلّوم \\
\hline$\cdot 0$. & 71 & $0 \square 0$ & 11 & جامعي \\
\hline \multicolumn{5}{|c|}{ علد سنوات الخبرة } \\
\hline A.Q. & 17. & TOL. & $\bar{v}$ & منخفضة (من 0 إلى أقل من OY) \\
\hline$\cdot \overline{\cdot 1 \cdot}$ & T. & T०[. & $\overline{v \cdot}$ & 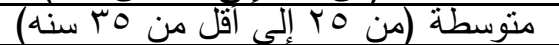 \\
\hline . प). & T. & $r \cdot \bar{T} \cdot$ & 7. & عالية (من هـاسنة فآكثر) \\
\hline \multicolumn{2}{|c|}{$Y \cdot, \Lambda)$} & \multicolumn{2}{|c|}{$T V, 7 T$} & المتوسط الحسابي \\
\hline \multicolumn{2}{|c|}{$7,0}$. & \multicolumn{2}{|c|}{$9, \cdot r$} & الإنحراف المعياري \\
\hline \multicolumn{5}{|c|}{ المشاركة الإجتماعية غير الرسمية } \\
\hline YIQ0 & $\varepsilon \mu$ & $\cdot 0_{0}$ & 1. & مشاركة منخفضة ( أقل من V درجات) \\
\hline . & V^ & $.01 \wedge$ & r & مشاركة منتوسطة (منة) V إلى أقل من با \\
\hline rवप्र & $\mathrm{Vq}$ & $\cdot \mathrm{QVV}$ & $10 \xi$ & مشاركة مرتفعة (من با إلى / ا درجة) \\
\hline \multicolumn{2}{|c|}{9,04} & \multicolumn{2}{|c|}{$1 \cdot, 7$} & المتوسط الحسابي \\
\hline \multicolumn{2}{|c|}{$0, T V$} & & & الإنحراف المعياري \\
\hline \multicolumn{5}{|c|}{ 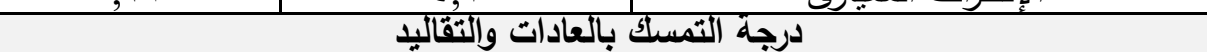 } \\
\hline$r \circ \overline{0}$ & VI & $0 \square$ & 11 & منخفضة (أقل من 1 درجات ) \\
\hline$\cdot \square \leqslant V$ & $9 \varepsilon$ & $7 \leqslant \square 0$ & $1 \times 9$ & منتوسطة ( من ^ 1 إلى أَّل من 17 درجة) \\
\hline IVDO & ro & . & 7. & مرتفعة (من 7 إلىى YY درجة) \\
\hline \multicolumn{2}{|c|}{$9, r$} & \multirow{2}{*}{\multicolumn{2}{|c|}{$\frac{11,0}{0,1}$}} & المتوسط الحسابي \\
\hline \multicolumn{2}{|c|}{$T, V$} & & & الإنحراف المعيارىى \\
\hline
\end{tabular}

المصدر: نتائج الدراسة الميدانية 


$$
\text { أوضحت النتائج الورادة بالجدول رقم (1) مايلي: }
$$

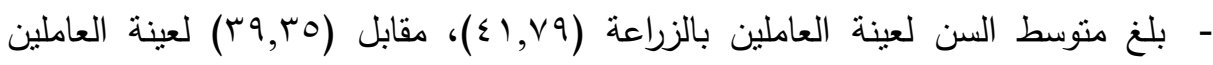
بالسياحة، وقد يرجع ذلك إلى أن مهنة السياحة مهنة حديثة وتحتاج إلى خبرة أقل، بينما

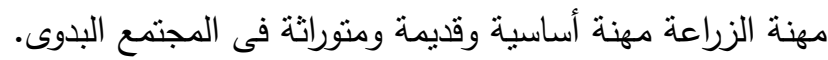

- وبالنسبة للحالة التعليمية يلاحظ إنخفاض نسبة التعليم الجامعى للمبحوثين العاملين بمهنة

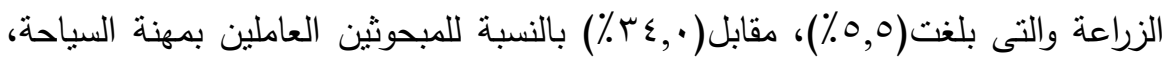

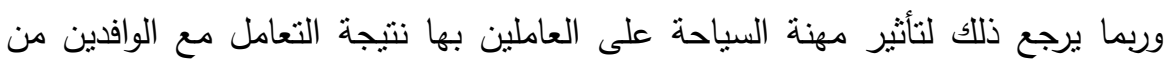
الوادي والدلتا والذين يتسمون بحالة تعليمية مرتفعة.

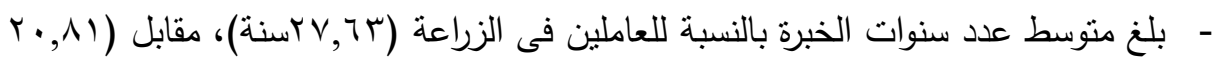

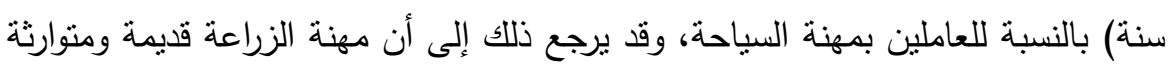

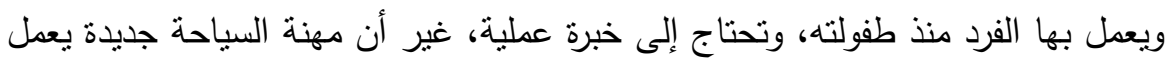
بها البدو من وقت غير بعيد وهى لا تحتاج إلى خبرة كبيرة مقارنة بمهنة الزراعة .

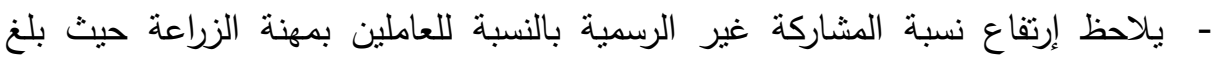

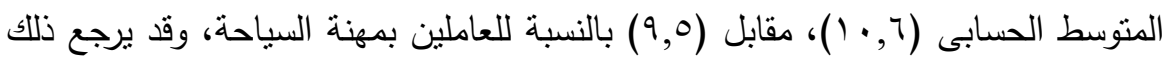

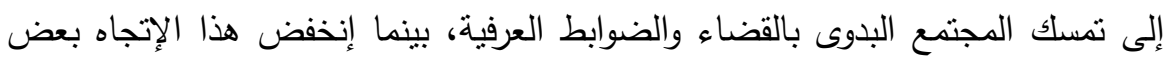

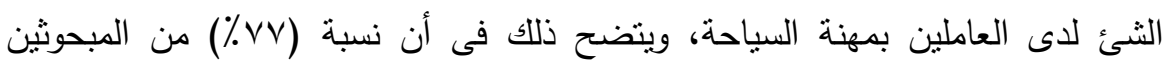

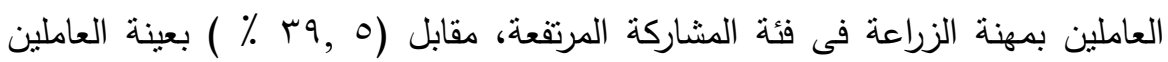
بمهنة السياحة.

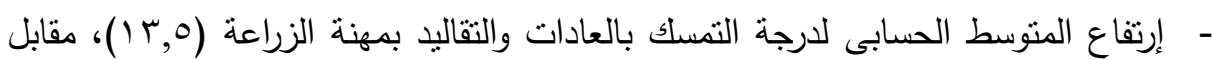

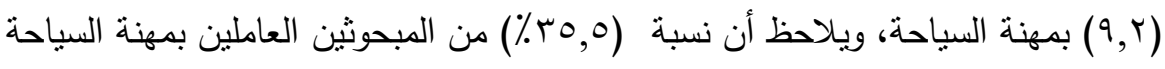

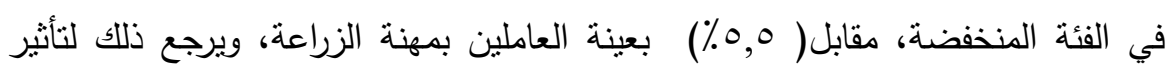
مهنة السياحة على العاملين بها من خلال التعامل مع الثقافات المختلفة الوافدة عليهر. 
ثانياً : النتائج المرتبطة بمستوى التغير الإجتماعى للمبحوثين بمهنتي الزراعة والسياحة

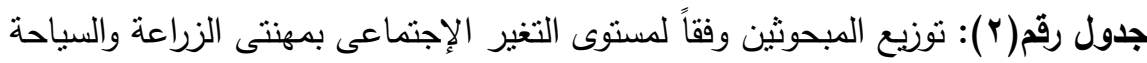

\begin{tabular}{|c|c|c|c|c|}
\hline \multicolumn{2}{|c|}{ العاملين بالسباحة } & \multicolumn{2}{|c|}{ العاملين بالزراعة } & \multirow{2}{*}{ مستوى التغير الإجتماعى } \\
\hline$\%$ & عدد & $\%$ & عدد & \\
\hline$\Gamma$, & 7 & $\Gamma, 0$ & 74 & منخفض ( أقل من ^1) \\
\hline r), & $\varepsilon r$ & $T \Sigma$, & 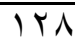 & متوسط ( من 1 1 إلى آقل من هץ) \\
\hline$\cdot, \times 7$ & 104 & $\varepsilon, 0$ & 9 & مرتفع ( من هب إلى .0) \\
\hline$\cdot, 1 \ldots$ & $r_{\ldots}$ & $\cdot, 1 \ldots$ & $r \ldots$ & المحموع \\
\hline
\end{tabular}

المصدر: نتائج الدراسة الميدانية

أوضحت النتائج الورادة بالجدول رقم(؟) نسبة (·,ـ؟ ٪) من المبحوثين العاملين بمهنة الزراعة فى فئة مستوى التغير الإجتماعى المتوسط، ونسبة (7٪\%) من المبحوثين العاملين

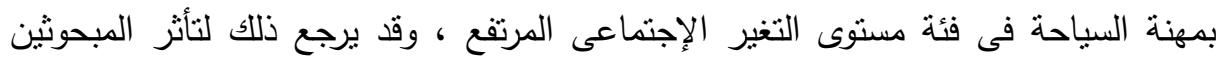

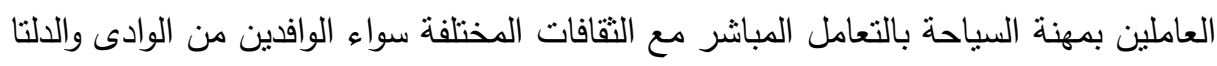
للعمل بالسياحة أو السائحين من مختلف النقافات، وتتفق هذه النتيجة مع دراسة (عبير عبد الندان الرحمن) على أن العمل بالمشروعات السياحية أثرت بشكل مباشر على ونى العادات والتقاليد

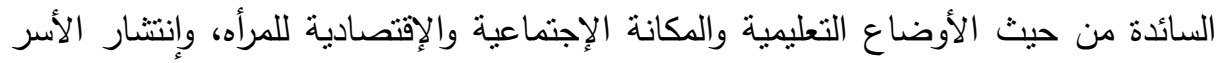

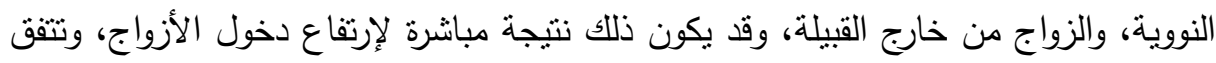
مع دراسة (محمود حسن ضيف) على أن مشروعات التتمية بشمال سيناء نتج عنها تغيرات إجتماعية حيث زاد إنتشار الأسر النووية، وشاع الزواج من أن أى قبيلة أو حسب رغبة رغبة الولد أو

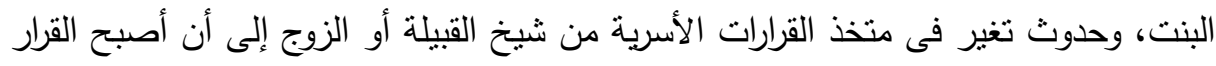

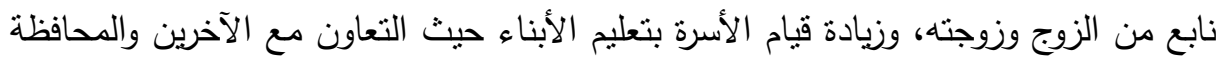

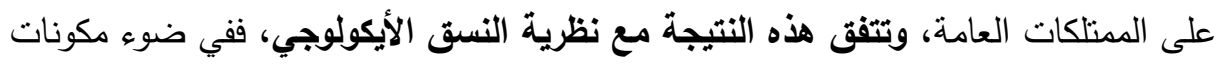
النسق الأيكولوجي الني تؤكد أن مدخلات النسق يقابلها مخرجات، وبإعتبار أن المجتمعات البدوية والتي تعمل بالزراعة أو السياحة نسق أيكولوجي يتضمن (الكائنات الحية - البيئة

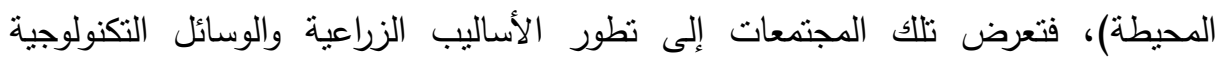
(المدخلات) قابل ذلك (مخرجات) تمثلت في زيادة الإهتمام بالتعليم، وإنتشار ظاهرة الأسرة 
النووية وتقلص الأسرة الممتدة، وإستقلال الأبناء عن آباءهم فى إتخاذ القرارات الأسرية، غير

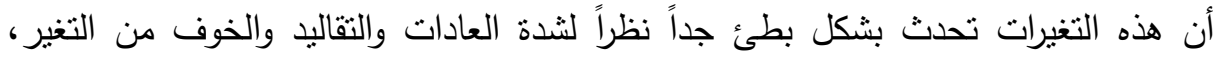

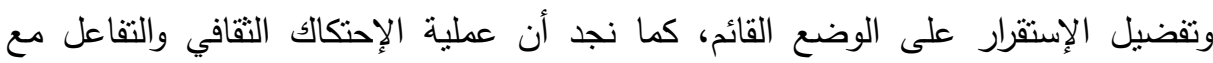

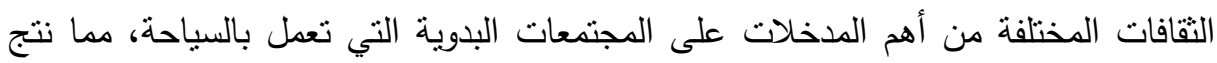
عنه حدوث بعض التغيرات الإجنماعية والنقافية (المخرجات)، تمنلت في تعلم اللغات

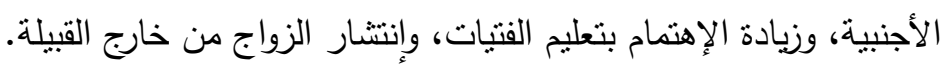
ثالثاً: النتائج المرتبطة بالتعرف على معنوية الفروق بين مستوى التغير الإجتماعى لمهنتى الزياعة والسياحة: يتتاول الجزء التالى عرض للنتائج البحثية المرتبطة بمعنوية الفروق بين مستوى التغير الإجتماعى للمبحوثين العاملين بمهنى السياحة والزراعة، وذلك من خلال إختبار (ت)، ومعامل الإرتباط البسيط لبيرسون وكانت النتائج كالتالى: أ- نتائج معنوية الفروق بين متوسطى درجة التغير الإجتماعى للمبحوثين العاملين بمهنتى

$$
\text { الزراعة والسياحة. }
$$

جدول رقم(ץ): نوزيع المبحوثين وفقاً لمتوسطى درجة التغير الإجنماعى بمهنتى الزراعة

$$
\text { والسياحة }
$$

\begin{tabular}{|c|c|c|c|}
\hline قيمة (ت) & الإِعراريافى & الحستوسب & درجة التغير الإجتماعى \\
\hline \multirow{2}{*}{ ع ז, זr } & $\varepsilon, 9 V$ & $Y, Y$, & للمبحوثين العاملين بمهنة الزراعة \\
\hline & $7, \xi$. & $r r, v q$ & درجة التغير الإجتماعى للعاملين بمهنة السياحة \\
\hline
\end{tabular}

المصدر: نتائج التحليل الإحصائى التئي

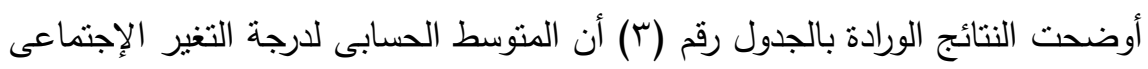

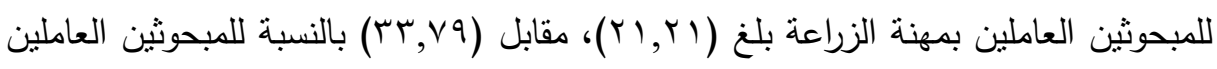
بمهنة السياحة، كما بلغت درجة الإنحراف المعيارى للمبحوثين العاملين بمهنة الزراعة

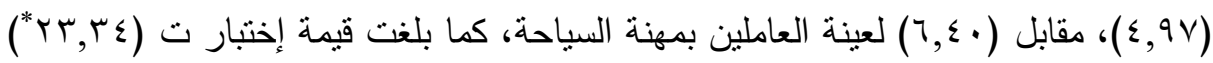
وهى معنوية عند المستوى الإحتمالى (0.,.) وذلك لصالح المبحوثين العاملين بمهنة السياحة، وقد يرجع ذلك إلى عملية الإحتكاك الثقافى التى يتعرض لها التها المبحوثين العاملين

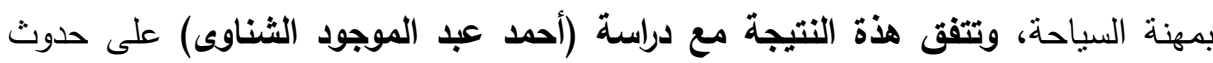

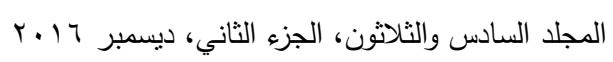


تغيرات إجتماعية وقيمية نتيجة للإحتكاك بالتقافات الوافدة سواء الوادي والدلتا أو الثقافات المختلفة الأخرى التى يتصل ويتعامل معها المبحوث، وتتثق هذه النتيجة مع نظرية الإرتباط

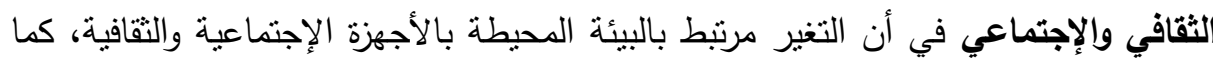

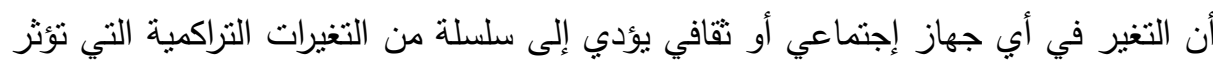

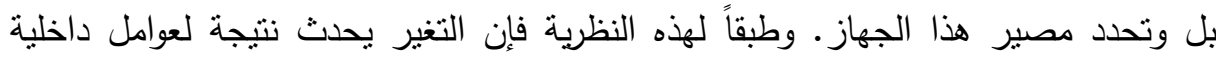

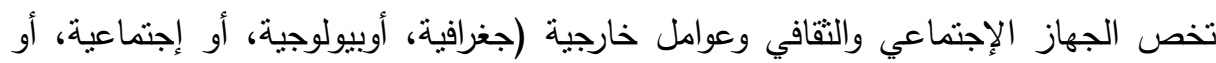

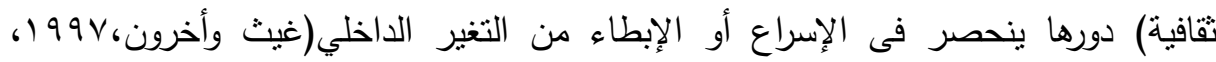

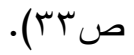
ب- النتائج المرتبطة بالتعرف على معنوية الفروق بن مستوى التغير الإجتماعى للمبحوثين العاملين بمهنتى الزراعة والسياحة

- لتحقيق الهدف الثالث للبحث والمرتبط بإختبار معنوية الفروق بين المتغيرات المدروسة من جهة وبين درجة التغير الإجتماعى من جهة أخرى، نم إستخدام معامل الإرتباط

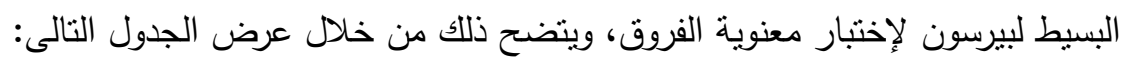
جدول رقم(؛): قيم معامل الإرتباط بين المتغيرات الإجتماعية المدروسة ودرجة التغير الإجتماعي للمبحوثين العاملين بمهنتى الزراعة والسياحة

\begin{tabular}{|c|c|c|}
\hline \multicolumn{2}{|c|}{ درجة التغير الإجتماعي } & \multirow[b]{2}{*}{ المتغيرات المدروسة } \\
\hline للمبحوثيثنين العباحملين & للمبحوئنين الزياعةلين & \\
\hline$\cdot, 7 \leqslant 1$ & $\overline{* *} \cdot, \wedge \leqslant \wedge-$ & 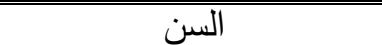 \\
\hline $3 *, 0,9$ & ${ }^{*} \cdot, V \leqslant Y-$ & عدد سنوات الخبرة \\
\hline${ }^{* *} \cdot, \vee \vee \vee 0$ & ${ }^{* *} \cdot, 01 Y$ & الحالة التعليمية \\
\hline${ }^{* *} \cdot, 0 \leqslant Y-$ & $\cdot, 00 \cdot-$ & درجة المشاركة غير الرسمية \\
\hline$\cdot, \wedge \vee 7-$ & $\cdot, 041-$ & درجة التمسك بالعادات والقيم \\
\hline
\end{tabular}




$$
\text { أوضحت النتائج الواردة بالجدول رقم (ع) مايلي: }
$$

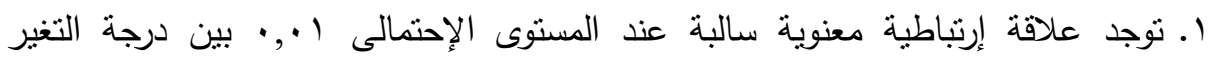

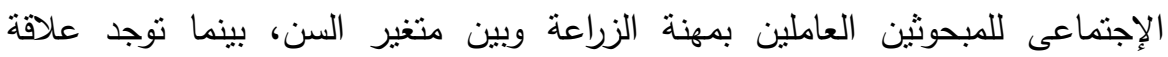

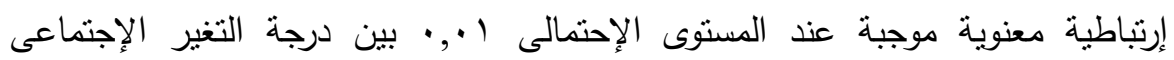

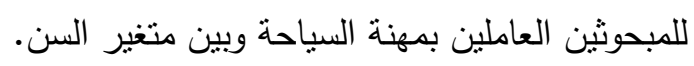
التفسير والتحليل: بالنسبة للمبحوثين العاملين بمهنة الزراعة فربما يرجع الإرتباط العكسى بين لين لهين

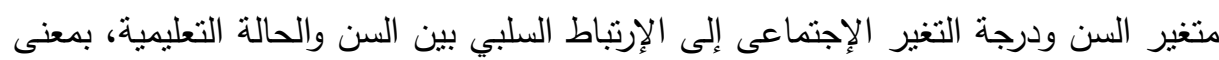

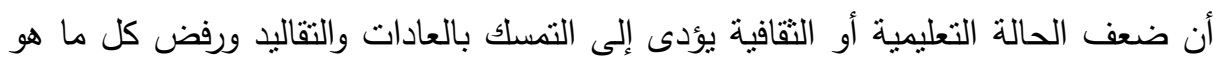
جديد خوفاً على العادات والثقاليد المرتبطة بالمجتمع البدوى، أما بالنسبة للمبحوثين العاملين

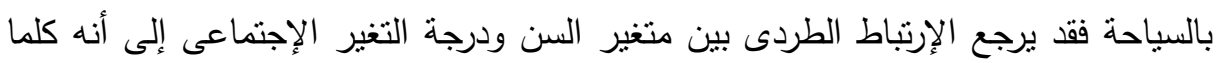

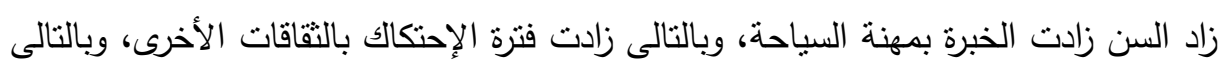
يحدث تغير إجتماعى. r. توجد علاقة إرتباطية معنوية سالبة عند المستوى الإحتمالى ل ب,, · بين درجة التغير الإجنماعى للمبحوثين العاملين بمهنة الزراعة وبين متغير عدد سنوات الخبرة، بينما توجد إنداهيه

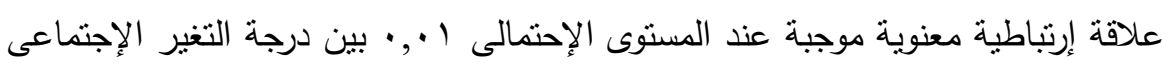

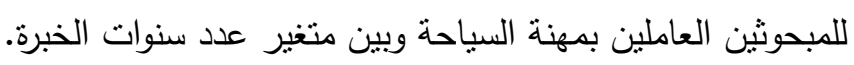
التفسير والتحليل: بالنسبة للمبحوثين العاملين بمهنة الزراعة فربما يرجع الإرتباط العكسى بين بين متغير عدد سنوات الخبرة وبين درجة التغير الإجتماعى إلى أنه كلما زادت عدد سنوات الخبرة

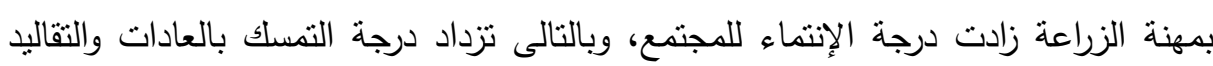

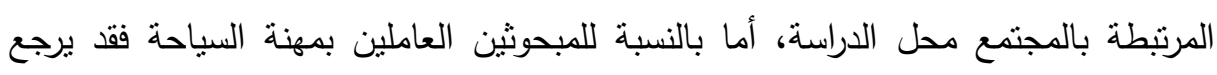
الإرتباط الطردى بين متغير عدد سنوات الخبرة وبين درجة التغير الإجتماعى إلى أنه كلما باليه

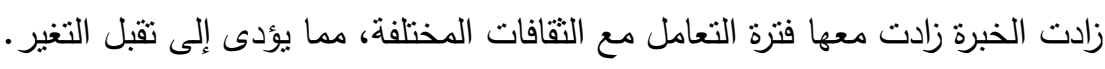

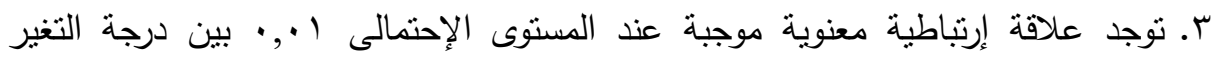
الإجتماعى للمبحوثين العاملين بمهنتي الزراعة والسياحة وبين متغير الحالة التعليمية.

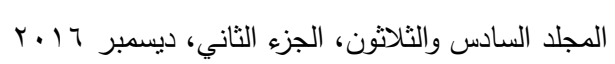


التفسير والتحليل: قد يرجع الإرتباط الطردى بين متغير الحالة التعليمية ودرجة التغير

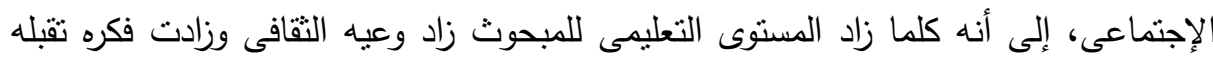

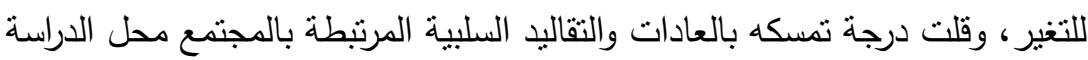

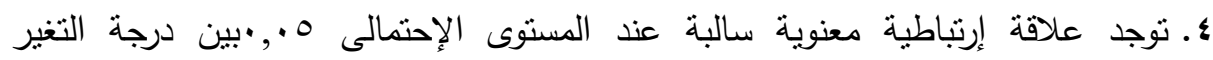
الإجتماعى للمبحوثين العاملين بمهنة الزراعة وبين متغير درجة المشاركة غير الرسمية،

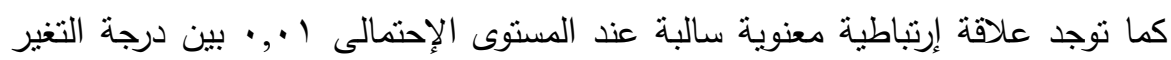
الإجتماعى للمبحوثين العاملين بمهنة السياحة وبين متغير درجة المشاركة غير الرسمية. التفسير والتحليل: فقد برجع الإرتباط العكسى بين متغير درجة المشاركة غير الرسمية ودرجة

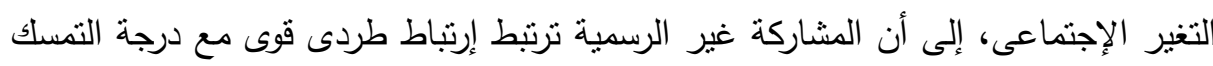
بالعادات والتقاليد الأمر الذي يعنى إرتفاع درجة التمسك بالأعراف والتقاليد والقوانين العرفية وعدم تقبل كل ما هو جديد بسهولة.

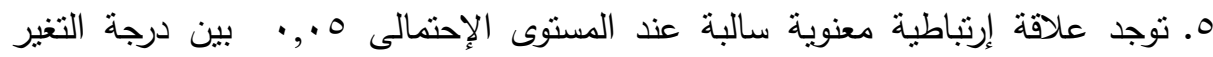

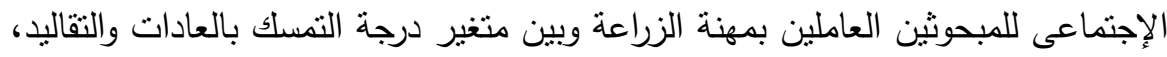

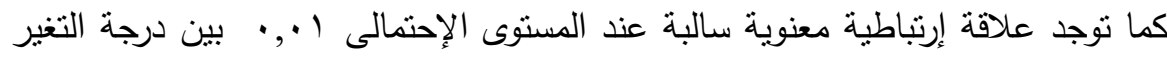
الإجتماعى للمبحوثين العاملين بمهنة السياحة وبين متغير درجة التمسك بالعادات والتقاليد. التفسير والتحليل:ربما يرجع الإرتباط العكسى بين متغير درجة التمسك بالعادات والتقاليد

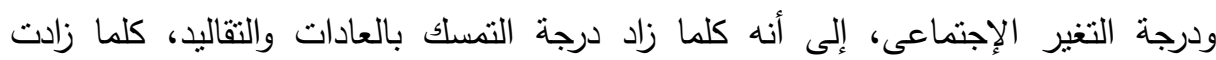
صعوبة تقبل التغير بمختلف أنثكاله وخاصة التغير الثقافى غير المادى والمتمنل فى العادات والتقاليد والقيم. - - بالنسبة للعاملين بمهنة الزراعة تتفق هذه النتائج مع دراسة (إنجي عبد الوهاب) على أن

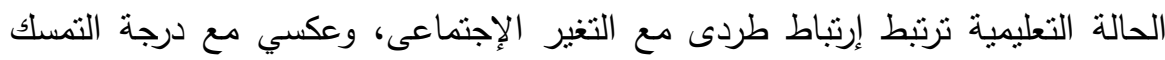
بالعادات والتقاليد ودرجة المشاركة غير الرسمية، كما تتفق مع دراسة ( فاطمة الظاهر)

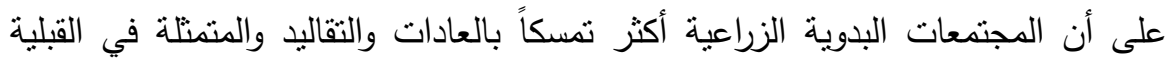


والعصبية، والتى تعد من المعوقات الأساسية لعمليات التغير المخططة (التتمية)، وتتفق

مع دراسة( إنتصار علي) في أن المشاركة غير الرسمية بالمجتمعات البدوية مرتفعة.

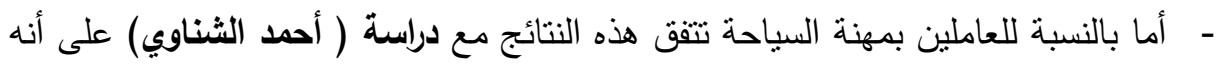

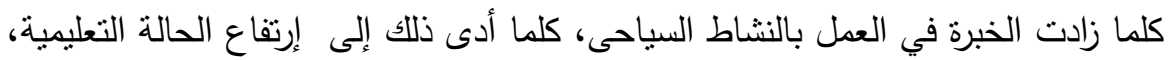
وتقل سمات القبلية والعصبية، وتتفق هذه النتائج مع نظرية النسق الأيكولوجي في ضوء

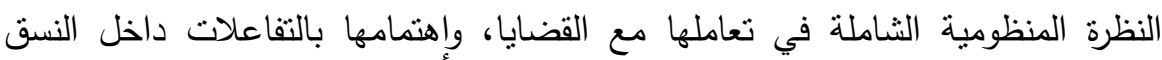
والآثار الناتجة عن هذه التفاعلات، وفي ضوء ما أوضحته نتائج البحث من حدوث تغيرات إجتماعية للمبحوثين من بدو سيناء نتيجة عمهم بكل من قطاعي الزراعة

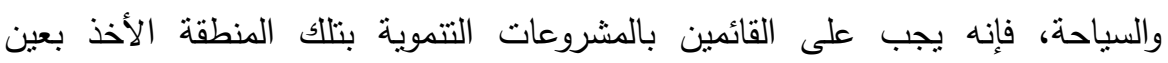
الإعتبار المحددات الفيزيقية والإجتماعية والثقافية المُشكلة للتكوين الإجتماعي للبدو بييئة سيناء وأيضاً شبكة العلاقات الإجتماعية فيما بينهم وذلك عند تخطيطهم وتتفيذهم للمشروعات التتموية الزراعية منها أو السياحية بمنطقة سيناء.

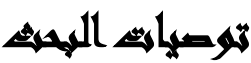

- بالنسبة لقطاع الزراعة: تشجيع البدو للتوجه إلى العمل بمهنة الزراعة حيث تعد مهنة

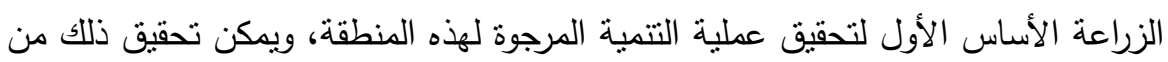

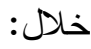
- الإهتمام بالتسويق وإقامة الأسواق القريبة لجذب العاملة إلى المهنة التى تعد الأساس الأول

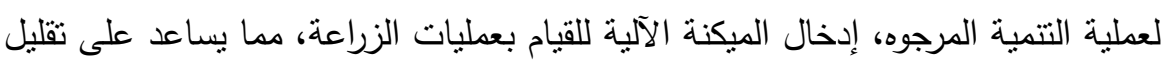
الجهد المبذول، وزيادة الإنتاجية. - زيادة عدد المرشدين الزراعيين المتخصصين، المقاومة السريعة للآفات والحشرات التي

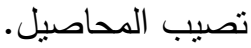




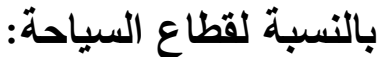

- إقامة برامج تدريبة للعاملين من البدو بمهنة السياحة للتعرف على الثقافة السياحية، والبعد

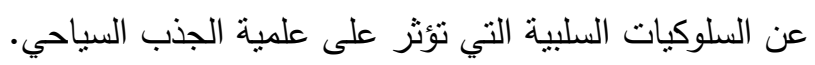

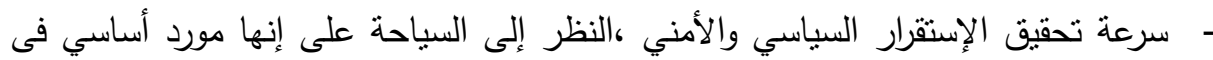
الإقتصاد المصري، وتتجيع السياحة الداخلية لتصبح واحدة من دعائم الإقتصاد القومي، بل وأن تكون بديلة للسياحة الأجنبية في وقت الأزمات.

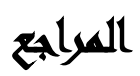

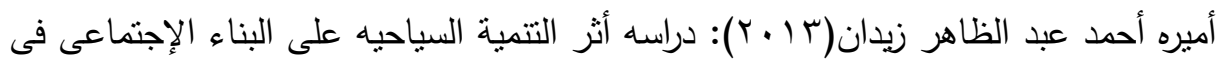

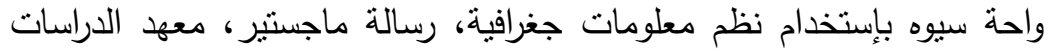

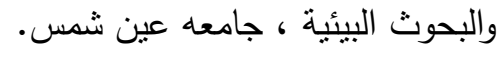

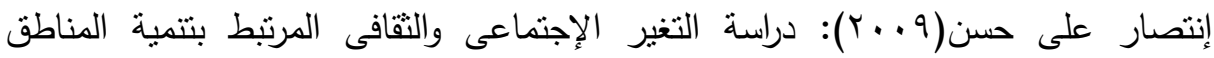

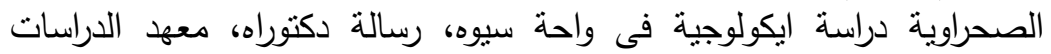

$$
\text { والبحوث البيئية، جامعة عين شمس اليكر }
$$

انجى العزب عبد الوهاب حافظ الديب(11 + ب): العلاقة بين المتغيرات الاجتماعية والبيئية

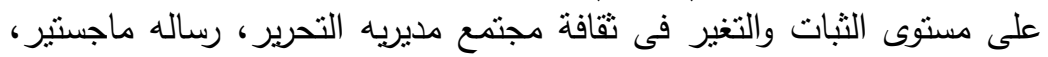

$$
\text { معهد الدراسات والبحوث البيئية، جامعه عين شمس فئي مديريه }
$$

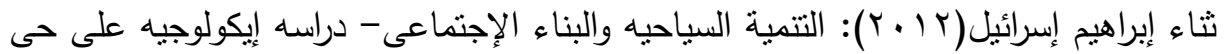

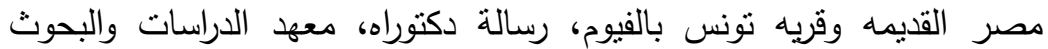

$$
\text { البيئية، جامعله عين شمس. }
$$

جابر عوض، حاتم عبد المنعم أحمد(؟99 (1)): البيئة والتتمية والخدمة الإجتماعية، دار المعرفة الجامعية، الإسكندرية.

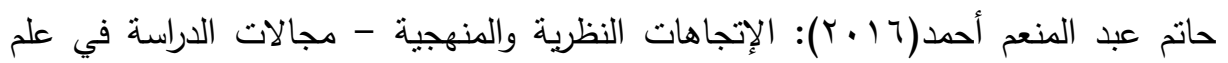

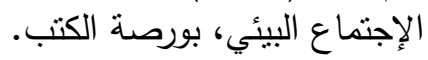

السيد حنفى عوض: (999 (199) علم الإنسان، ظافر للطباعة، الزقازيق،. 


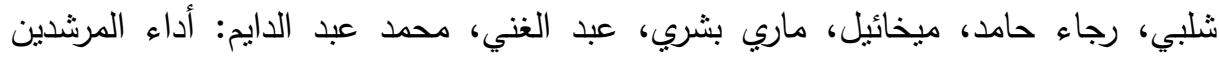

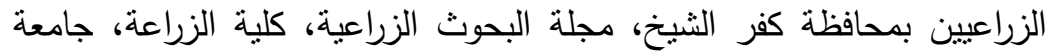

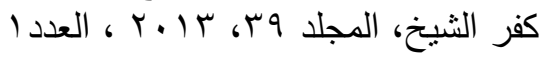

عبد الباسط عبد المعطى(997 (199): البحث الإجتماعى محاولة نحو رؤية نقدية لدنهجه وأبعاده، دار المعرفة الجامعية ، الإسكندرية

عبد الحليم رضا( 911 () البحث فى الخدمة الإجنماعية ، القاهرة، دار النقافة للطباعة والنشر

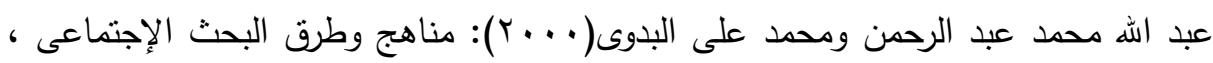
دار المعرفة الجامعية، الإسكندرية.

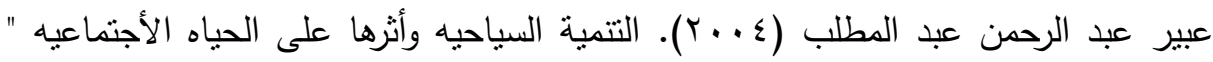

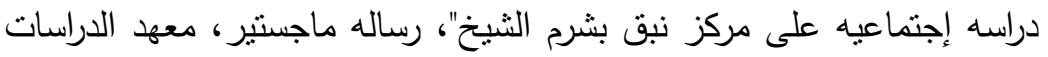

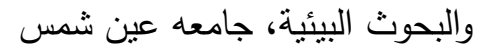

لويس كامل مليكه(1909 (): البحث الإجتماعى ومناهجه وأدواته ، القاهرة ، مكتبة القاهرة،

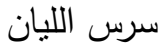

محمد عاطف غيث وآخرون(997 (199 دراسات في التتمية والتخطيط الإجتماعى، دار المعرفة

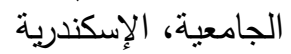

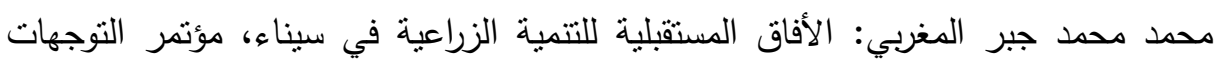

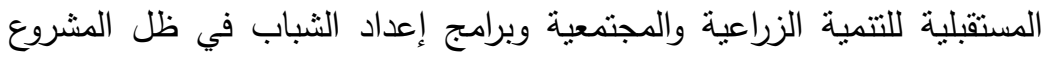

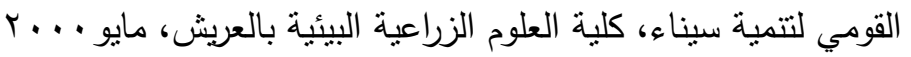

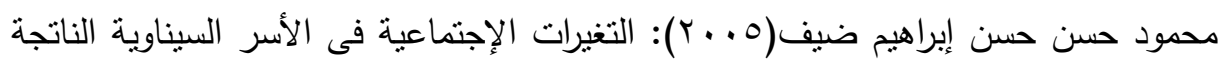

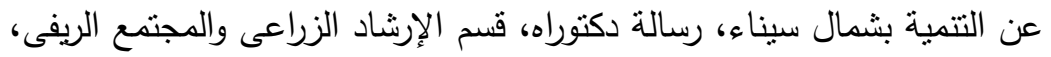
كلية الزراعة، جامعة القاهرة

مديرية الزراعة بالعريش، والإدارة الزراعية بمركز بئر العبد، بيانات غير منشورة ، محافظة

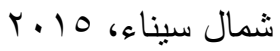

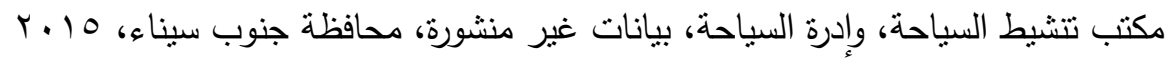

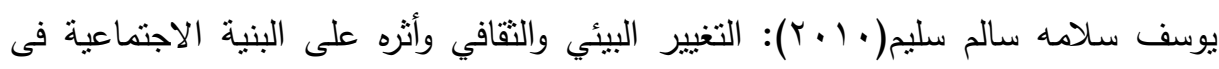

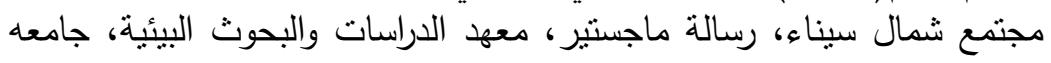


Dernberger,R.F, Reform Development in Rural China: Studies on the Chinese Economy, Economic Development and Cultural Change, vol.4, No(3).

Fair Child Dictionary of Sociology and Related Sciences 3rd edition, K.H.P, New York. U.S.A, 1985

Keller, J .W., Rural Development in the United States: Connecting Theory,Practice, and Possibilities, Journal of American Planning Association, vol.6, 1996.

Krejcie Robert,v. \& Morgan Daryle,w., Determining Sample Size for Research Activities. In Edncational and Psychological Measarment, Published by college Steion, Burham, North Carolina, U.S.A, 1970.

Lippitt, Visualizing. Lajolla, Canada Univ. Associate press, 1973.

Robert Christie Mill, tourism - the international Business New York (London prentice - Hall.inc, 1990)

Rotolo, T., Occupational Ecology: An Evolutionary Theory of Social Composition of Occupations, The University of Arizona, 1995. 


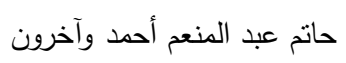

\title{
STUDY OF SOCIAL VARIABLES ASSOCIATED WITH AGRICULTURE AND TOURISM COMPARATIVE STUDY ON THE ECOLOGY OF PROFESSIONS - SINAI BEDOUIN
}

\author{
Ahmed, H. A. ${ }^{(1)}$; Hassan, E. A. ${ }^{(2)}$ and Abd El Aziz, H. H. M. ${ }^{(3)}$ \\ 1) Institute of Environmental Studies and Research, Ain Shams \\ University. 2) Social Studies Department of the Desert Research Center \\ 3) Social Studies Department of the Desert Research Center.
}

\begin{abstract}
The current study aims to identify social characteristics of respondents employed in agriculture and tourism, and identifies the level of social changes resulting from work in both sectors, as well as identify the nature of the relationship between social variables studied and the level of social changes associated with agriculture and tourism professions at the study area.

To achieve these goals, social survey methodology is used in the sample, Central was chosen (Chekka in North Sinai governorate), (Sharm el Sheikh, South Sinai governorate), with the highest number of workers in agriculture and tourism career respectively who have experience for more than 15 years working in both professions, and rebelled against 200 was selected from farming, and rebelled against 200 of tourism professionals identified according to krigsi equation and Morgan, have been collecting field data from January until 2016 April 2016 using questionnaire interview.
\end{abstract}

$$
\text { المجلد السادس والثثاثون، الجزء الثاني، ديسمبر } 17 \text { ـ }
$$


The study indicated a number of results:

1. The rising of age mean of employees in farming profession (41.79) comparing to employees in tourism (39.35 years).

2. The rising of experience mean of employees in farming profession (27.63 years), comparing to ( 20.8 years) for the profession of agriculture.

3. The rising of informal participation mean of employees in farming profession (10.6), comparing to ( 20.8) for the profession of agriculture.

4. The rising of degree of adherence to customs and traditions mean of employees in farming profession (13.5), comparing to (9.2) for the profession of agriculture.

5. There are differences between the average degree of social change of respondents employed in tourism and agriculture for the benefit of tourism profession.

6. There is a correlation between the degree of social change and the studied variables (age-education-years of experience-informal social participation-the degree of adherence to customs and traditions) of respondents working in my profession, tourism and agriculture.

\section{One of the most important research recommendations:}

-For the agriculture sector: attention to marketing and administration of nearby markets to attract workforce to farming, which is the first Foundation of the development process.

For the tourist sector: training programmers for employees of the tourism profession nomads to identify tourism culture and distance from the negative behaviors that affect the operation of attractions. 